Revista de Comunicación y Salud, 2020, Vol. 10, oㅡ 2, pp. 149-183

Editado por Cátedra de Comunicación y Salud

ISSN: 2173-1675

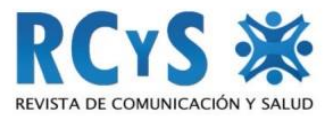

Enviado 14/08/2020

Aprobado 13/10/2020

\title{
PANDEMIA, CONSUMO AUDIOVISUAL Y TENDENCIAS DE FUTURO EN COMUNICACIÓN
}

\author{
Pandemic, audiovisual consumption and future trends in communication
}

\author{
Edorta Arana Arrieta ${ }^{1}$ \\ Universidad del País Vasco/Euskal Herriko Unibertsitatea. España \\ edorta.arana@ehu.eus \\ Libe Mimenza Castillo \\ Universidad del País Vasco/Euskal Herriko Unibertsitatea. España \\ libe.mimenza@ehu.eus \\ Bea Narbaiza Amillategi \\ Universidad del País Vasco/Euskal Herriko Unibertsitatea. España \\ bea.narbaiza@ehu.eus
}

\begin{abstract}
Artículo enmarcado en varios proyectos de investigación en los que trabajan los firmantes. 1) Proyecto de la convocatoria Universidad-Sociedad de la UPV/EHU titulado "Applika+: creando puentes entre la creación y los consumos audiovisuales" (US20/21), en colaboración con EITB, Tabakalera y el Observatorio Vasco de la Cultura, septiembre 2020-septiembre 2022. 2) Proyecto de la convocatoria Universidad-Sociedad de la UPV/EHU titulado "Applika: creación, evaluación y consumo audiovisual" (US17/40), en colaboración con EITB, noviembre 2017-diciembre 2019. 3) Proyecto de la convocatoria Universidad-Sociedad de la UPV/EHU titulado "Respuesta a la crisis por parte de los medios de comunicación en euskera" (US18/17), en colaboración con Hekimen, noviembre 2018-diciembre 2020. 4). Proyecto del MINECO titulado "Nuevas solidaridades, reciprocidades y alianzas: la emergencia de espacios colaborativos de participación política y redefinición de la ciudadanía" (CSO2017-82903-R), enero 2018-diciembre 2021. 5) Proyecto conjunto de un grupo de investigadores de la UPV/EHU, del centro IKER de Baiona y la Universidad Pública de Navarra titulado "Gaztesare: prácticas e identidad multilingüe entre los jóvenes vascos", noviembre 2019-diciembre 2021.
\end{abstract}

\section{Resumen}

Este artículo hace un repaso a los cambios más importantes que se han producido en el campo de la comunicación a raíz de la pandemia causada por la COVID-19. Cuestiones como el aumento de los consumos mediáticos, sobre todo en los soportes digitales y en red, la importancia de la información en esta crisis y el crecimiento de los contenidos de ficción y entretenimiento son algunos de los aspectos analizados en el texto. Para este trabajo se ha contado con una gran cantidad de fuentes documentales que ofrecen datos muy actualizados y, además, se han utilizado los resultados de una investigación

\footnotetext{
${ }^{1}$ Autora para correspondencia: Edorta Arana Arrieta, Universidad del País Vasco, edorta.arana@ehu.eus.
} 
Pandemia, consumo audiovisual y tendencias de futuro en comunicación

propia con un panel de estudiantes universitarios. En la primera parte, y desde una mirada global, se hace referencia a distintos países del mundo para, después, situar el trabajo en el ámbito del Estado español. En el apartado relativo al panel de universitarios vascos, el texto desgrana los consumos y las actitudes de los jóvenes para con los medios y las plataformas de comunicación online. En la sección final del artículo, se reflexiona sobre el momento actual y las tendencias de futuro en el cambiante mundo de la comunicación. Entre ellas caben destacar dos, aquella que sitúa la crisis actual en un momento de mutación y expansión en las diversas prácticas comunicativas y la de atribuir posiciones innovadoras a los más jóvenes en cuanto al cómo, qué y dónde conectarse a los medios y recursos de comunicación en red.

Palabras clave: Pandemia; Medios de comunicación audiovisual; Medios online; Información; Consumo; Estudiantes universitarios; Redes sociales.

\begin{abstract}
This article delves into the most important changes that have taken place in the field of communication in the context of the pandemic caused by COVID-19. Aspects such as the increase in media consumption, especially in digital and online media, the importance of current affairs in this crisis and the growth of fiction and entertainment content are some of the issues mentioned in it. A large number of sources offering very up-to-date data are used and, in addition, we have included the results of our own research based on a panel of university students. In the first part, and from a global perspective, we offer references of different countries of all over the world to, later, locate the theme within the Spanish boundaries. In the section including the data from the panel of Basque university students, the article describes the aforementioned young people's media consumption and attitudes about both legacy and online media. In the final section of the article, we comprise some reflections on the current moment and future trends in the changing world of communication. Among the conclusions, two should be highlighted: to place the current crisis at a time of change and expansion in the various communication practices and to assign to the youngest innovative positions in the how, what and where consume media, specially, online media.
\end{abstract}

Keywords: Pandemic; Audiovisual media; Online media; Information; Media consumption; University students; Social media.

\title{
Cómo citar el artículo
}

Arana Arrieta, E., Mimenza Castillo, L. y Narbaiza Amillategi, B. (2020). Pandemia, consumo audiovisual y tendencias de futuro en comunicación. Revista de Comunicación y Salud, 10 (2), 149-183. doi: https://doi.org/10.35669/rcys.2020.10(2).149-183

\section{INTRODUCCIÓN}

2020 pasará a los libros de historia con la referencia a un virus que trastocó el día a día en casi todas sus facetas. Es probable que más allá de las cifras de muertos, 
infectados y las dramáticas curvas logarítmicas que las ilustren, aflorarán reflexiones sobre la incidencia que la COVID-19 ha tenido en el modo en que se construyen las sociedades, las relaciones de poder entre ellas y dentro de cada una y el papel que juega la comunicación. Estamos seguros de que en ese relato se mencionarán, entre otros, las nuevas formas de comunicación mediada, las contradicciones sociales sobre el proceso de digitalización y la convergencia de las grandes empresas tecnológicas. En fin, y en una sola palabra, de Internet, como sistema en el que, entre otros, se materializan los distintos medios y soportes de comunicación. Porque Internet se ha convertido en protagonista de este encierro a nivel mundial y porque entre las distintas brechas culturales, económicas, sociales y tecnológicas que existen la conexión ha sido y es el múltiplo común en la respuesta global al aislamiento: conectarse a la red para superar la "distancia social" y relacionarse, conectarse a la red para trabajar, conectarse a la red para entretenerse, conectarse a la red para hacer deporte, conectarse a la red para recibir contenidos culturales, conectarse a la red para saber qué está pasando.

Desde el punto de vista de la comunicación son muchos los aspectos que han surgido durante esta pandemia, como por ejemplo la estructura sobre la que orbita el poder en Internet; la creación, transmisión y consumo de los contenidos y entre estos últimos los de información; la relevancia de lo audiovisual en la cultura actual y el peso de la ficción en las prácticas y usos sociales, entre un largo etcétera.

Tras la aparición del coronavirus, el consumo de noticias ha aumentado y todos los indicadores observados durante años han alcanzado máximos semana tras semana número de visitas, usuarios, duración-, y las redes sociales han ampliado su penetración social y tiempo de conexión que acaparan (The Social Media Family, 2020). Además, durante el confinamiento ha crecido la preocupación ciudadana por la proliferación de noticias falsas (Perez-Dasilva et al., 2020) y aunque ha caído la inversión publicitaria en medios (Rivas, 2020), han surgido nuevos productos mediáticos y nuevas rutinas de trabajo para los profesionales de la comunicación (Berkeley News, 2020).

Y todo esto se da en un contexto general en el que el proceso convergente entre las telecomunicaciones, la informática y los medios de comunicación afecta tanto a la producción y la transmisión como a la recepción de los contenidos, también de los audiovisuales.

...la convergencia no debe ser vista como un estadio, sino como un proceso y, como tal, un fenómeno cambiante: su grado debe evaluarse teniendo en cuenta las innovaciones tecnológicas, pero especialmente su apropiación social. Por otra parte, sus consecuencias se manifiestan en planos distintos según se tenga en cuenta la dimensión empresarial, la de las tecnologías o la de los contenidos. De las interacciones entre las tres dimensiones se derivan consecuencias culturales y sociales que revisten de relevancia la observación de ese proceso. (Prado, 2009, p. 33)

Precisamente son los aspectos relativos a la recepción, uso y consumo de los medios tradicionales y aquellos en red que permiten la transmisión de contenidos 
Pandemia, consumo audiovisual y tendencias de futuro en comunicación

audiovisuales, los que se están consolidando como motores del cambio. El cómo vemos y vivimos los distintos soportes de la comunicación y sus contenidos marcarán el devenir de los medios que, aunque, en el caso de los de carácter audiovisual tienen todavía a la televisión como su soporte principal, el panorama está evolucionando rápidamente (Kantar Media, 2020).

Las nuevas actitudes para con los medios, los secuenciales y sobre todo aquellos en línea, se han manifestado de modo más nítido entre las personas jóvenes (Tubella et al., 2008; Ramos, \& Pac, 2019). Es un sector de la sociedad más abierto a ver los contenidos audiovisuales en cualquier momento y lugar, utilizando distintos aparatos de recepción y accediendo de modo más autónomo a aquellos contenidos generalistas 0 muy específicos que le resulten de interés.

La digitalización está recorriendo todavía sus primeras décadas y necesitará tiempo para escribir su propio camino. Por encima del fuerte impacto que ya ha causado, la experiencia pone de manifiesto que los cambios en la oferta, los usos y consumos son un terreno de análisis que hay que trabajar día a día.

De ahí la pertinencia de afianzar algunas de las líneas de investigación que se centran en el análisis de los usos y consumos, los niveles de gratificación, la evolución en la oferta de contenidos audiovisuales y la reacción del público (Lozano, 2018; Santiago, 2019).

Aunque tradicionalmente se ha señalado que existen dos estructuras paralelas en el mundo de la investigación de audiencia, la proveniente de la propia industria del sector y la de carácter académico, parece que hoy en día ambas tienden a confluir en sus intereses (Arana, 2011). Porque, aunque se ha escrito que la investigación comercial muchas veces ha jugado un "rol de parte", nadie parece poner en duda que ha sido un sector que a nivel internacional y también para el caso español ha alcanzado estabilidad y se ha convertido en instrumentos que cuantifican y arbitran los vaivenes del mercado audiovisual. Eso sí, poniendo de manifiesto muchas veces cierta tendencia a sobrevalorar las novedades tecnológicas y a sobredimensionar las grandes empresas del sector televisivo y, ahora, del resto de proveedores de contenido audiovisual, desde cualquiera de sus soportes de difusión.

Resulta especialmente interesante aquella aproximación metodológica que aporta lo mejor de las técnicas cuantitativas y cualitativas. En particular, estas últimas porque nos ayudan a entender los motivos y las valoraciones que hacen los usuarios, más allá de los datos concretos, por muy llamativos que estos sean.

Entre las distintas investigaciones llevadas a cabo en las universidades apuntaremos algunos de los trabajos y autores más significativos (Astigarraga, 2017), en muchos casos nos referiremos a los estudios centrados en los sectores más jóvenes de la sociedad y en cómo están interiorizando el cambio de paradigma en la comunicación mediada (Livingstone \& Sefton-Green, 2016; Livingstone \& Bober, 2004; Evans, 2011; Gray \& Lotz, 2012, entre otros).

Revista de Comunicación y Salud, 2020, Vol. 10, oㅡ 2, pp. 149-183 
Pandemia, consumo audiovisual y tendencias de futuro en comunicación

Así, por ejemplo, Barkhuus (2009) analiza cualitativamente la evolución en los consumos audiovisuales en Internet y televisión entre los jóvenes estudiantes universitarios norteamericanos.

González Aldea y López Vidales (2011) desde un punto de vista más cuantitativo profundizan en los gustos de los jóvenes españoles de entre los 18-25 años y su paulatino desapego para con la televisión tradicional, por no permitir niveles más altos de interactividad y estar encasillada en los mismos contenidos y formatos.

Bondad-Brown (2011) en su tesis doctoral compara los consumos de la televisión tradicional y aquellos ofertados por los servicios audiovisuales online. Desde el marco analítico de los Usos y las Gratificaciones (Flores-Ruiz \& Humanes-Humanes, 2014) estudia las motivaciones de la audiencia por los distintos contenidos audiovisuales.

La investigación de Arango-Forero (2013) es otra de las referencias a considerar sobre los consumos que los jóvenes, en este caso colombianos, hacen en la televisión tradicional e Internet.

Resultan especialmente fructíferos los trabajos de Pavón-Arrizabalaga (2014), sobre los adolescentes y sus consumos de medios; Landabidea (2013), centrado en las percepciones sociales sobre la televisión; y la ya citada Astigarraga (2017), que analiza los consumos audiovisuales en televisión e Internet de los jóvenes universitarios vascos.

Como hemos visto, el estado actual de la investigación sobre los usos en comunicación, la relación con sus contenidos audiovisuales y las audiencias pone de manifiesto la importancia que adquieren aquellos trabajos centrados en los jóvenes (Garitaonandia et al., 2019). Sin duda, desde el convencimiento de que las pautas de consumo y las opiniones que manifiestan estos jóvenes pueden ser indicios de las pautas sociales futuras.

Hablar de juventud y medios digitales, es hacerlo de un fenómeno que está consiguiendo modificar de forma radical los modelos de uso del tiempo y las relaciones sociales. Es decir, el consumo que las y los jóvenes hacen de las redes digitales, y concretamente de Internet, está transformando, no sólo el ocio y las formas de interacción de este segmento de la población con su entorno, sino, además, por extensión, de la sociedad en su conjunto. Puede decirse que, por primera vez, son los individuos más jóvenes los que toman la iniciativa, actuando como conductores (drivers) en lo que se refiere al empleo de los medios y las funciones que emprenderán de forma intercomunicada. Algo así como una "socialización ascendente" en las TIC (Tecnologías de la Información y la Comunicación) (Rubio, 2010: 201)

En esa misma línea, el trabajo titulado "La juventud como early adopter del cambio tecnológico: un análisis de los jóvenes aragoneses (España)" apuntala la relevancia de los jóvenes en estos nuevos procesos de socialización 
Pandemia, consumo audiovisual y tendencias de futuro en comunicación

Si consideramos a los jóvenes como early adopters, estos ejercerían una función de liderazgo a través de la cual otros grupos sociales, especialmente los potencial adopters, los tendrían como referencia, hasta el punto de esperar sus consejos e informaciones sobre la innovación en cuestión para terminar incorporándola en sus vidas (Rogers, 1983: 249) (Ramos \& Pac, 2019. 3)

Para un análisis exhaustivo sobre la relación entre los jóvenes españoles y la tecnología resultan muy interesantes trabajos como los de Puente et al. (2015) y Campo, Pereira y Simöes (2016) centrados en Portugal y, en especial, los de Feixa (2000 y 2014) sobre las que el denomina generacion@ y \#generación.

\section{OBJETIVOS}

El coronavirus ha sacudido muchas de las bases de la sociedad actual, entre otras las relativas a la comunicación. En poco tiempo, el rol que los medios tradicionales y los nuevos soportes de la comunicación online jugaban en nuestro día a día han sufrido cambios importantes.

Este artículo toma como objetivos los de recopilar información diversa sobre la evolución en el cómo, qué y cuándo de los consumos mediáticos durante el confinamiento; tratar de discernir aquellos aspectos más novedosos; $y$, en particular, ahondar en tendencias detectadas en el público joven. El presente artículo, además, señala una serie de ideas clave en el actual y futuro marco de la comunicación, más allá de los vaivenes coyunturales que se hayan podido producir en los índices de audiencia.

\section{METODOLOGÍA}

En la preparación de este artículo se han utilizado simultáneamente dos líneas de trabajo. A través de la primera, se ha profundizado en la incidencia que la crisis generada por la COVID-19 ha tenido en el consumo de medios audiovisuales y en el tráfico de información en Internet, los contenidos más utilizados y el papel que han ocupado entre ellos la información, la ficción y el entretenimiento. Para ello se ha recurrido a una gran cantidad de fuentes documentales entre las que cabe citar Comscore, Reuters, NiemanLab, Kantar Media, Instituto IMOP, AIMC, Barlovento y Netflix, y tomando como referencia temporal el primer cuatrimestre de 2020, fecha en la que se desata la crisis del coronavirus, y siempre con apuntes a los meses previos y posteriores al confinamiento. También se hace un repaso rápido de algunas fuentes documentales secundarias que sitúan el tema del cambio de paradigma que se ha dado en la comunicación. En esta primera parte empezaremos por dibujar marcos muy globales de análisis y referencias geográficas y temporales amplias, para después centrarnos en España.

En segundo lugar, y con el fin de conocer en este periodo tan relevante de la historia actual los usos de las tecnologías de la información y la comunicación (TIC) y los consumos de los distintos productos audiovisuales por parte de los jóvenes 
Pandemia, consumo audiovisual y tendencias de futuro en comunicación

universitarios, se ha recurrido a lkusiker, un panel de más de 700 estudiantes de la Universidad del País Vasco/Euskal Herriko Unibertsitatea (UPV/EHU). Las y los miembros del panel han contestado durante el confinamiento una serie de cuestionarios (utilizamos para ello la plataforma www.encuestafacil.com) que les han sido subministrados a través de WhatsApp y que nos permiten conocer de primera mano y de modo exhaustivo y rápido sus consumos audiovisuales y prácticas de comunicación mediadas por equipamientos tecnológicos. Los datos que aquí barajamos tienen lindes temporales (primer cuarto de 2020) y socio-demográficos (jóvenes universitarios, entre los 18-23 años) bien definidos y su generalización siempre debe estar supeditada a esta consideración. Sin embargo, la información que ofrece el panel da una visión clara de unas tendencias que sin duda son replicadas en entornos sociales más amplios, en un futuro a corto plazo.

En la parte final del presente documento, se incluyen una serie de reflexiones e ideas, desde una mirada prospectiva, tratando de acercarnos las previsibles consecuencias de los cambios tecnológicos y sociales acelerados por el coronavirus.

\section{ALGUNAS DE LAS CLAVES DEL MOMENTO ACTUAL}

La llegada de Internet en la última década del siglo pasado se enmarca en un largo proceso en el que todavía estamos y que ha provocado importantísimos cambios en la sociedad (Castells, 2009). Su rápida expansión también ha revolucionado el ecosistema mediático: los soportes tradicionales -papel, radio, televisión- han dado muestras de resiliencia aunque hayan perdido peso, y la industria de medios hubiera comenzado a girar el timón hacia lo digital, propulsada por los no menos impactantes cambios en los hábitos de consumo entre los usuarios (Madinaveitia, 2020). Las pequeñas y grandes empresas de comunicación han tenido que reubicarse y escribir un nuevo guion en el que los usuarios navegan por Internet en una nube de datos y contenidos ilimitada.

En ese terreno de juego apareció la COVID-19 y avivó una serie de tendencias ya presentes. Y lo hizo provocando en la red dos fenómenos muy interesantes: la práctica universalización y normalización de las TIC y un importante crecimiento en el consumo de medios de comunicación (Nielsen et al., 2020). Coincidiendo con las primeras consecuencias de la declaración del estado de alarma la pregunta que flotaba en el aire era "¿qué está pasando?", y la búsqueda de respuestas trajo consigo un incremento inusitado en el número de visitas a los distintos sitios web.

Es este el contexto en el que afrontamos esta investigación y en el que profundizaremos desde varios puntos de vista. En primer lugar, repasaremos lo ocurrido en la red en lo relativo a la información; a continuación, analizaremos el fenómeno de las redes sociales y las aplicaciones de mensajería, esto es, nos adentraremos en el estudio de las formas de comunicación interpersonal inmediata e ininterrumpida; después, desarrollaremos el tema de la evolución en los consumos de la televisión tradicional y de las plataformas de streaming; y, por último, nos centraremos en el consumo de los jóvenes. 


\subsection{Información en la red}

Con la pandemia, el consumo de noticias creció en todas partes del mundo. La necesidad de obtener información se concretó en países tan diferentes como Alemania, Argentina, Estados Unidos, Corea del Sur, España, o Reino Unido, cuya ciudadanía rastreó información a través de redes sociales, buscadores, portales de vídeo y aplicaciones de mensajería, o una combinación de todos ellos (Nielsen et al., 2020). El aumento del consumo de noticias se aprecia claramente en los seis países que analiza el informe titulado "Navigating the 'infodemic': how people in six countries access and rate news and information about coronavirus" y que abarca el periodo que va de finales de marzo y principios de abril de 2020. Los medios online y la televisión fueron, sin duda, las vías más utilizadas para acceder a la información sobre la crisis sanitaria, como se puede ver en el primero de los gráficos.

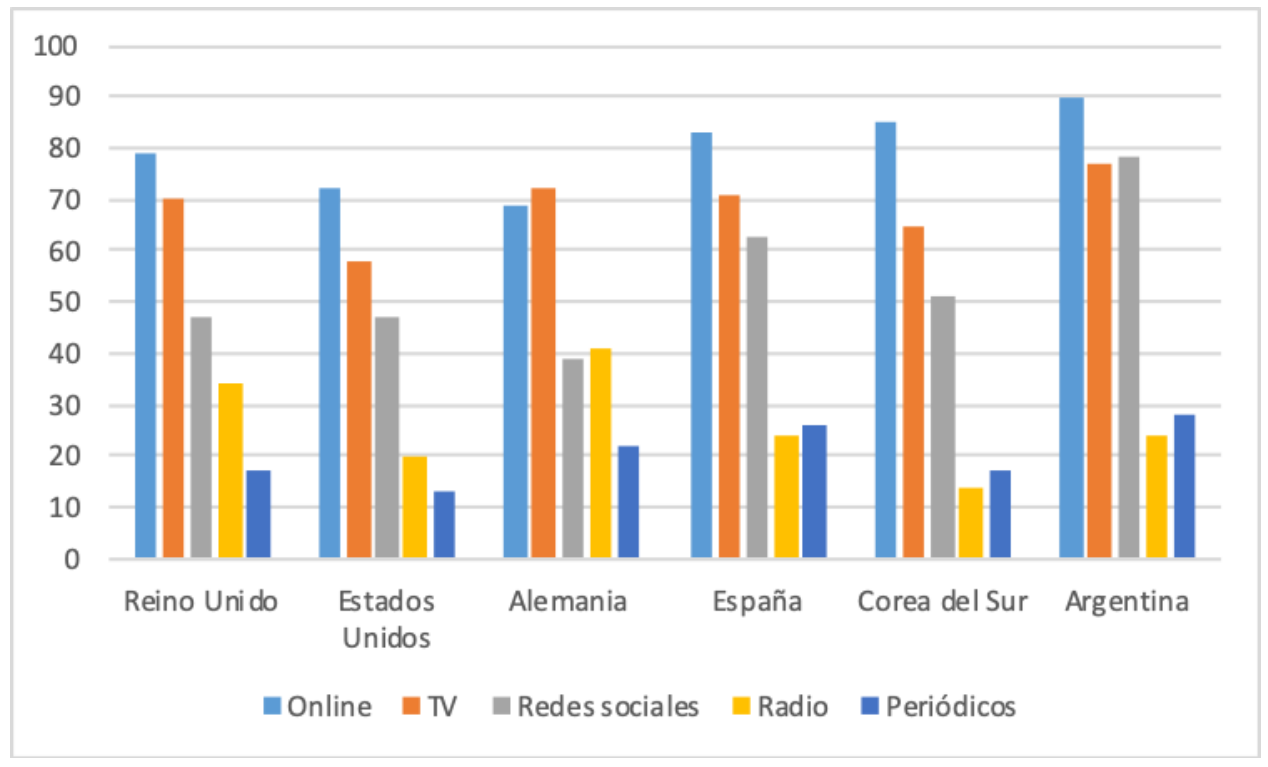

Gráfico 1. Utilización de los distintos sistemas para recabar información sobre la COVID-19.

Fuente: Nielsen et al. (2020).

Los recursos online son los más utilizados, por la ciudadanía de estos seis países, seguido de la TV. La cuota de las redes sociales ocupa el tercer lugar, aunque es bastante diferente en Alemania o Argentina, y la radio y los periódicos ocupan los últimos puestos en relevancia como fuentes de información sobre el coronavirus.

Como norma general se puede asegurar que el consumo de noticias aumentó de modo generalizado, pero el mismo informe revela también diferencias demográficas reseñables: mientras que los jóvenes identifican los medios digitales -y a menudo las redes sociales- como su primera fuente de información, los segmentos de edad más adulta recurren principalmente a la televisión. Por lo tanto, la crisis de la COVID-19 pone de manifiesto lo global del impulso de buscar información, pero también diversidad 
Pandemia, consumo audiovisual y tendencias de futuro en comunicación

en los modos de conseguirla. Las grandes empresas de información (periódicos, televisiones, agencias de noticias...) canalizan una gran parte de esta demanda, pero no son las únicas fuentes reconocidas, ni los únicos soportes a los que la gente recurre. De tal modo que aquella parte de la población que se mantiene online de modo ininterrumpido consulta sitios web, redes sociales $u$ otros recursos en línea. La información se extiende así a través de los distintos medios y soportes, en las esferas pública y privada de comunicación.

La evolución al alza en el consumo de información se ha mantenido durante el confinamiento. La agencia Comscore (2020), que mide las audiencias en Internet y los comportamientos de los usuarios digitales, señaló que, a la luz de los datos de unos 40 portales de noticias seleccionados para su análisis, la semana que más visitas a sitios de noticias registró en todo el año fue aquella entre el 16 y el 22 de marzo, con una diferencia importante (aumentaron un $18 \%$ respecto a la semana previa y un $68 \%$ frente al mismo periodo del mes anterior). Asi mismo, la cantidad de información consumida sobre cada uno de los países a estudio experimentó un crecimiento superior a la media: subieron un $89 \%$ las visitas de noticias por países, respecto a los días comprendidos entre el 16-22 de marzo y el 17-23 de febrero, y en el mismo periodo la subcategoría de noticias generales aumentó un $62 \%$. Esta proliferación de noticias de proximidad se explica sin duda por la necesidad de la ciudadanía de entender cómo había de afectar la crisis a su día a día y en su ámbito geopolítico más cercano (Molay \& Essling, 2020).

Más allá del dato agregado global, tras recopilar información de cinco países europeos (Francia, Alemania, Italia, España y Reino Unido), se publicaron en marzo también datos sobre portales de noticias de interés general (Gevers, 2020a y 2020b). La intensificación en el número total de visitas a portales de noticias demuestra cuándo y con qué rapidez la pandemia captó la atención del público. Según dichos estudios, las visitas a los portales de información general se mantuvieron estables hasta la semana del 10 al 16 de febrero de 2020; a partir de ahí el consumo italiano se disparó al mismo ritmo que la dramática situación de la república transalpina durante el estado de emergencia y, en el resto de países, el interés aumentó gradualmente hasta el 15 de marzo. Desde el inicio de año, el número de visitas creció un $50 \%$ en Francia, un $29 \%$ en Alemania, un $142 \%$ en Italia, un $74 \%$ en España y un $44 \%$ en Reino Unido (hasta el 15 de marzo). De ahí en adelante, sin embargo, a pesar de que el consumo de noticias siguió al alza, y en algunos países de modo muy claro, la tasa de crecimiento se estancó: desde principios de año, el consumo de noticias generales aumentó un $68 \%$ en Francia, un 57\% en Alemania, un $125 \%$ en Italia, un $87 \%$ en España y un $51 \%$ en Reino Unido (hasta el 22 de marzo).

En lo que se refiere al consumo de información, destacó también la avidez a nivel mundial por los temas económicos y financieros. El consumo asociado a la categoría "economía" aumentó hasta el 22 de marzo un 21\% en Francia, un 34\% en Alemania, un $90 \%$ en Italia, un $47 \%$ en España y un $39 \%$ en Reino Unido. Dicha predilección temática se activó temporalmente incluso antes que por las noticias de carácter general (Comscore, 2020).

Revista de Comunicación y Salud, 2020, Vol. 10, nº 2, pp. 149-183 
Por otra parte, el interés por la información sobre cada uno de los países también se dinamizó en Italia a partir del 10 de febrero y en el resto a partir del 2 de marzo. La magnitud del crecimiento de la información local es muy destacable (más acentuada que sobre economía y finanzas, anteriormente mencionadas). Así, en 2020 el consumo de noticias locales aumentó un $125 \%$ en Francia, un $101 \%$ en Alemania, un $105 \%$ en Italia, un $158 \%$ en España y un $45 \%$ en Reino Unido (hasta el 22 de marzo). El peso de lo local fue muy superior al crecimiento de las noticias internacionales en el caso de Francia, Alemania y España; similar en Italia, aunque ligeramente ascendente, y decreció un $6 \%$ en el Reino Unido. El timing en la expansión de la pandemia en los distintos países, las respectivas medidas de aislamiento aplicadas y las características de sus correspondientes ecosistemas mediáticos pueden explicar esas diferencias. Pero de lo que no hay duda es que entre los aspectos reseñables a nivel internacional durante la crisis de la COVID-19 en la primera parte de 2020, la información ha sido imprescindible y los medios de comunicación han contribuido a socializar la crisis y a ejemplarizar los modos en los que la población debía actuar ante ella. Sin embargo, uno de cada tres ciudadanos declaró que los mass media han exagerado la importancia de la pandemia; aunque, paralelamente, el nivel de conocimiento sobre el coronavirus fue estadísticamente mayor entre quienes utilizaron los medios como fuente de información (Nielsen et al., 2020).

También merece la pena mencionar un fenómeno tan complejo como es el del bombardeo informativo y la navegación, en muchos casos rodeada de noticias falsas y otras no contrastables, lo que ha sido denominado infodemia. Es decir, la sobreabundancia de información que resulta imposible verificar e incluso asimilar socialmente. Un peligro que va más allá del coronavirus pero para el que la Organización Mundial de la Salud, en su declaración de septiembre de 2020, propone:

...gestionar la infodemia promoviendo la difusión oportuna de información precisa basada en datos científicos y probatorios, dirigida a todas las comunidades, y en particular los grupos de alto riesgo; y previniendo y combatiendo la propagación de información errónea y falsa, siempre respetando la libertad de expresión. (OMS, 2020)

Según lo dicho, el consumo de información aumentó en plena espiral vírica y las audiencias de medios de comunicación alcanzaron máximos niveles históricos. Pese a lo dicho, estas cotas tan elevadas y los cambios que ilustran no tienen por qué entenderse como un signo inequívoco de "una nueva normalidad" en los consumos de medios. Según los expertos del NiemanLab (Benton, 2020) es difícil mantener la atención durante mucho tiempo, da igual la importancia del acontecimiento o del tema tratado, la vida de la gente continúa, por lo que conocer los mecanismos que permiten mantener el interés de la audiencia e influir en ella seguirá siendo un reto importante no sólo para los medios de comunicación, sino también para la sociedad en general.

Como ya hemos señalado, el interés por la COVID-19 llegó a su punto álgido a mediados de marzo y para finales de mes se registraba un descenso en las mediciones internacionales. Se puso de manifestó así cierto agotamiento por recibir y tener que 
procesar tanta información. ¿Pero por qué ocurrió eso? Según el instituto Reuters, hay tres razones que pueden haber contribuido a que la gente evitara premeditadamente las noticias: la información de actualidad deprime a la gente; hace que se sienta impotente porque no puede influir en los acontecimientos; las percibe como superficiales, sensacionalistas e imprecisas, cuando no falsas (Kalogeropoulos, 2020). Asimismo, existen estudios en marcha que buscan correlacionar el consumo excesivo de noticias y el aumento de la ansiedad, lo que ha venido a coincidir con algunas de las recomendaciones de organismos de salud mental que aconsejaron moderar el consumo de medios durante el encierro. Por otra parte, en el portal Wired se habló de la preocupante consecuencia de este cansancio, ya que hacía necesario seguir manteniendo la atención de la audiencia porque sólo se afrontaría adecuadamente la pandemia con una ciudadanía bien informada (Bedingfield, 2020). Pocos ponen en duda la relación entre el consumo de información y el nivel de comprensión de la crisis $y$, a la luz de los datos, los lectores de noticias están mejor informados.

\subsection{Hiperconectividad}

Como ya ha quedado dicho, el consumo de información y los niveles de audiencia de medios aumentaron durante la crisis del coronavirus, pero no han sido esas las únicas ratios que se han incrementado. Entre otras cosas porque la información no sólo se consultó en las páginas web de los medios tradicionales, también tuvo un peso enorme en las redes sociales o las aplicaciones de mensajería. Y, por supuesto, el uso de ambos se generalizó porque están ligados tanto a la información como, sobre todo, al entretenimiento, las relaciones personales de amistad o familiares o con el sistema educativo -la utilización de recursos de enseñanza online de modo masivo ha sido otra de las novedades del confinamiento-. La hiperconectividad es pues una de las claves de esta segunda década del siglo XXI en la que vivimos.

La presencia constante y ubicua de las tecnologías digitales en casi todas las actividades cotidianas, gracias en gran medida a la proliferación de dispositivos móviles con acceso a Internet, está propiciando la consolidación de una "era de la hiperconectividad", que se caracteriza además por la sobreabundancia informativa y por la cultura de la velocidad. No son pocos los autores, sin embargo, que alertan de los posibles perjuicios que la conexión digital permanente puede acarrear, ya sean de orden neurológico, afectivo o social. (Serrano-Puche, 2013)

Las redes sociales y las aplicaciones de mensajería protagonizan esta época en la que prima la inmediatez y, aunque chocan con el modelo de negocio clásico de los medios de comunicación, también son un lugar común para el consumo de información. Cada vez más personas acuden a los buscadores y a las plataformas de información. Ejemplos de ello son el hub especial del buscador Google (https://www.google.com/covid19: "COVID-19 Información y recursos") o el "Coronavirus (COVID-19): Information Center" que presentó la red social Facebook (https://www.facebook.com/coronavirus info). Youtube también facilitó en algunos países información sobre el coronavirus ofrecida por las autoridades sanitarias y, de 
igual manera, Twitter difundió tuits procedentes de medios de comunicación e instituciones públicas. Asimismo, muchas de las principales plataformas también brindaron espacios publicitarios para difundir mensajes de salud pública. Aunque las cifras globales varían de un país a otro, los porcentajes incluidos en el gráfico número 2 indican claramente la tendencia global de utilizar buscadores y redes sociales para informarse sobre el coronavirus (Nielsen et al., 2020). Destacan las cifras de Argentina, Corea del Sur o España, por encima de las del Reino Unido, EEUU y Alemania.

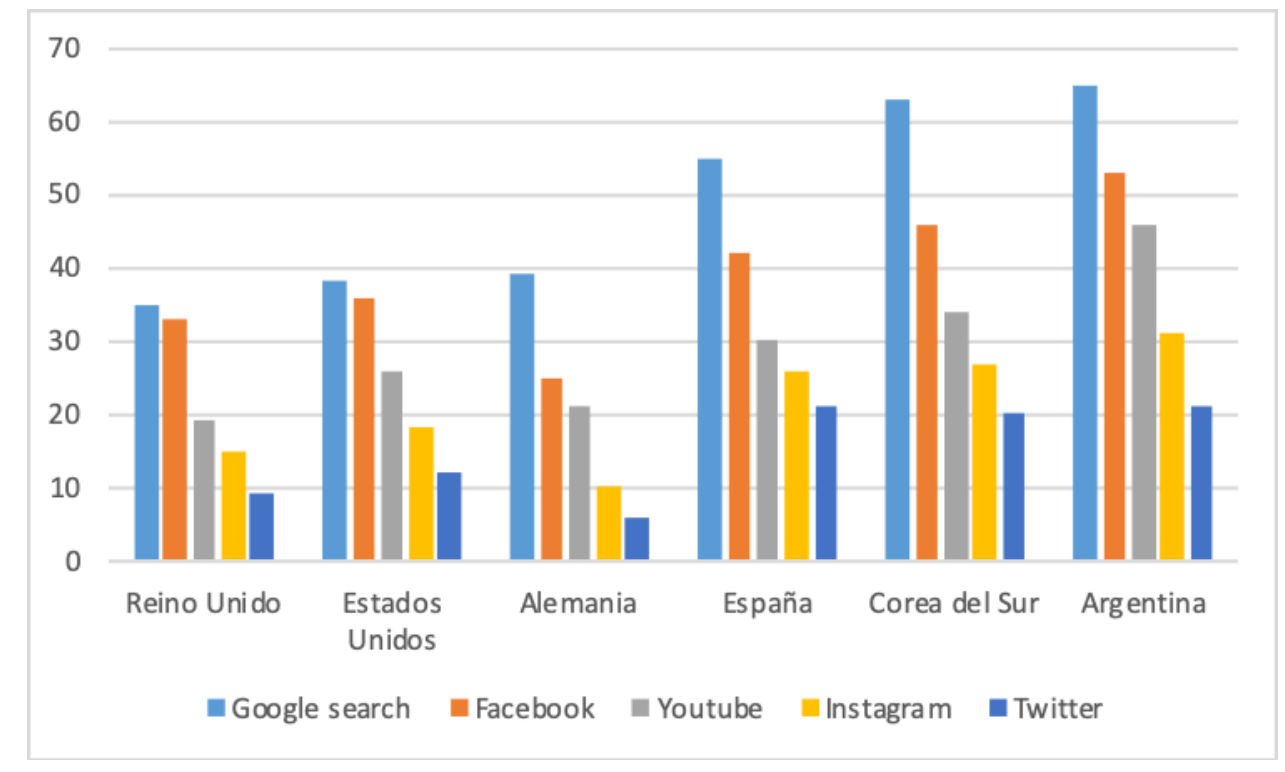

Gráfico 2. Plataformas online utilizadas para acceder a información sobre la COVID-19. Fuente: Nielsen et al. (2020).

Además, los jóvenes de los distintos países expresaron más confianza en las redes sociales que las cifras del total de la población, en especial en aquellas redes más recientes y que tienen una componente visual más evidente, como Instagram, Snapchat o TikTok. El dato más destacado en el citado informe de Nielsen et al (2020) es el de Argentina: casi la mitad de los jóvenes de entre 18 y 24 años (49\%) declaró haber utilizado Instagram para recibir contenidos sobre el COVID-19.

Las aplicaciones de mensajería también se unieron a la explosión en el consumo de información. WhatsApp, por ejemplo, lanzó un chatbot de la Organización Mundial de la Salud y limitó la capacidad de los usuarios para reenviar mensajes como medida para combatir la desinformación. Se ha prestado mucha atención a estos entornos acotados porque permiten la comunicación privada entre individuos y grupos que intercambian entre ellos un gran volumen de información, pero siguen siendo plataformas difíciles de investigar, tanto por la falta de acceso a los datos como por la encriptación de las redes. No obstante, parecen afianzarse algunas tendencias generales entre los usuarios y principalmente en lo que se refiere a la extensión y frecuencia de su uso: casi cuatro de cada diez encuestados estuvo activo en un grupo de Facebook sobre el coronavirus y más de la mitad en grupos de WhatsApp. 
Pandemia, consumo audiovisual y tendencias de futuro en comunicación

La conectividad ininterrumpida acelerada por el coronavirus ha traído como consecuencia que las redes sociales y las aplicaciones de mensajería sean utilizadas no solo para recibir información, sino para otros muchos usos.

En el caso de las redes sociales, la proliferación en el número de visitas fue gradual y sólo en la semana del 9 de marzo de 2020 se notó un incremento (probablemente este fenómeno estuvo relacionado con un uso cotidiano muy extendido de las redes sociales, y el aumento hace referencia al confinamiento y al hábito de uso de cada país). El crecimiento en el uso de portales y aplicaciones en redes sociales llegó al $12 \%$ en Francia, al $31 \%$ en Italia, al $48 \%$ en España y al $12 \%$ en el Reino Unido, mientras que en Alemania se mantuvo en la misma cota (Gevers, 2020a y 2020b).

En cuanto al uso de aplicaciones de mensajería instantánea, también es evidente el impacto de las medidas de confinamiento en cada país. El consumo se mantuvo estable hasta la semana del 17 al 23 de febrero de 2020. Una semana más tarde, las cosas comenzaron a cambiar en Italia, días antes de que se anunciara la cuarentena en todo el país, que se produjo el 9 de marzo. En el resto de países los datos comenzaron a variar a partir del 9 de marzo (España declaró el estado de alarma el 14 de marzo y un día después el confinamiento de la población, Francia inició la cuarentena el 17 de marzo, Reino Unido el 24 de marzo y Alemania lo hizo el 24 del mismo mes).

Según las mismas fuentes, tomando como referencia el 2020, y hasta el 22 de marzo, el consumo de aplicaciones de mensajería instantánea aumentó un $70 \%$ en Francia, un 30\% en Alemania, un $90 \%$ en Italia, un $97 \%$ en España y un $49 \%$ en Reino Unido.

A la luz de los datos analizados y atendiendo a su contexto, es de subrayar el incremento generalizado en el uso de Internet. Las cifras de conexión crecieron en todo el mundo a medida que avanzaba la pandemia de la COVID-19. Han sido millones los que han estado trabajando desde sus casas y no menos los que han continuado con sus estudios una vez que se cerraron las escuelas y las universidades (Li \& Lalani, 2020). También han recurrido a la red aquellos que trataban de superar el distanciamiento social provocado por la crisis sanitaria y hablar con sus familiares y amigos, informarse de lo que estaba pasando, aprender más sobre cocina, hacer deporte... y, en especial y de modo muy destacado, consumir contenidos audiovisuales: series, películas, vídeos musicales, documentales... lo que ha llevado a que una parte importante de la población haya pasado muchas horas al día en plataformas online y streaming.

En el siguiente apartado haremos un repaso de la relevancia social que ha adquirido lo audiovisual al inicio de la pandemia.

\subsection{Audiovisual}

La importancia creciente de lo audiovisual en los consumos culturales es evidente y ha venido de la mano del incremento en la penetración social de Intenet y de la

Revista de Comunicación y Salud, 2020, Vol. 10, nº 2, pp. 149-183 
Pandemia, consumo audiovisual y tendencias de futuro en comunicación

velocidad en la transferencia de datos en la red de redes. Sus consecuencias han sido muchas, pero queremos destacar entre ellas que el lenguaje audiovisual se ha convertido para mucha gente en el estándar tanto para la ficción como para la información, ya que esta progresiva audiovisualización de la comunicación también se ha hecho notar en las noticias (Deogracias, 2015). La influencia de lo audiovisual ha afectado, como no podía ser menos, a otro medio que utiliza ese mismo lenguaje, la televisión. Y es que, además de sentir el impacto de una red social como Youtube desde su nacimiento en 2005, en el último periodo se ha producido una expansión importantísima de los nuevos operadores audiovisuales y en particular de plataformas de streaming. La televisión tradicional ha visto tambalear su hegemonía tanto en cuanto a modelo de negocio como a estrategias de programación o audiencia (Bustamante, 2003).

Lo visual ha sido desde siempre parte muy relevante de la cultura contemporánea occidental y con la tecnología online esa importancia no ha hecho más que aumentar (González, 2018). La narrativa llevada a lo audiovisual es socialmente más impactante. El relato gana en fuerza, en cercanía y en veracidad, y se ha generalizado el uso de dispositivos que permiten acceder a dichos contenidos audiovisuales en cualquier sitio y en el momento deseado. Las pantallas de móviles y ordenadores, además de las de televisión conectada, se han convertido en objetos cotidianos para una inmensa mayoría de la población. La penetración de las pantallas de distintos tamaños es un dato relevante y también lo es el tiempo que el público les dedica. Las Tecnologías de la Información y la Comunicación están muy extendidas y el nivel de alfabetización funcional permite su uso generalizado (Martinez, 2019). La crisis del coronavirus lo ha puesto negro sobre blanco.

La pandemia ha demostrado que en momentos de crisis social el consumo de medios crece y que la gente recurre especialmente a aquellos de carácter audiovisual no solo para cubrir sus necesidades de información sino también en busca de contenidos de entretenimiento. En el contexto del coronavirus, las cifras revelan que a partir de la crisis sanitaria aumentaron los consumos de medios y especialmente aquellos audiovisuales: el $67 \%$ de los encuestados vio más informativos que antes, el $51 \%$ incrementó su consumo de contenidos de ficción de pago y el $45 \%$ utilizó más televisión que anteriormente (Statista, 2020ㄹ). Asimismo, entre las TIC que ganaron en importancia se encuentran la mensajería instantánea (45\%), las redes sociales (44\%) o los videojuegos (36\%). Como ya hemos analizado, en el marco de estas tendencias se produjo el aumento del consumo de información, tanto de medios digitales como de redes sociales o aplicaciones de mensajería, la televisión y las plataformas de streaming, tal y como detallaremos a continuación.

En el caso del Estado español, se observa durante el confinamiento un aumento del tiempo dedicado a la televisión (Kantar Media, 2020). Según el informe especial publicado por la consultoría Barlovento Comunicación (2020), en marzo, el tiempo medio ante la gran pantalla fue de 284 minutos (233 minutos en 2019). Por si fuera poco, llama especialmente la atención el nivel de consumo del 15 de marzo, en el que se inició el confinamiento: 344 minutos. Además, estas dos cifras corresponden a la

Revista de Comunicación y Salud, 2020, Vol. 10, nº 2, pp. 149-183 
media de la población (se conectaran o no la televisión), pero si nos fijamos solo en aquellas personas que realmente vieron la tele, el tiempo de consumo de estos telespectadores fue de 371 en marzo y 426 minutos el 15 de ese mes. Datos record en el histórico del consumo televisivo español.

Pero más allá de las ratios audimétricas de la televisión tradicional, es imprescindible mencionar las plataformas OTT (Over-The-Top), la televisión conectada y los contenidos audiovisuales en streaming. Todos ellos tienen un elemento en común, son del ámbito del audiovisual online. Y aunque no todos los consumos audiovisuales online consiguen los mismos datos, es de destacar que la visualización en streaming supuso en 2019 el 57,6\% del tráfico descargado a nivel mundial (Sandvine, 2020):

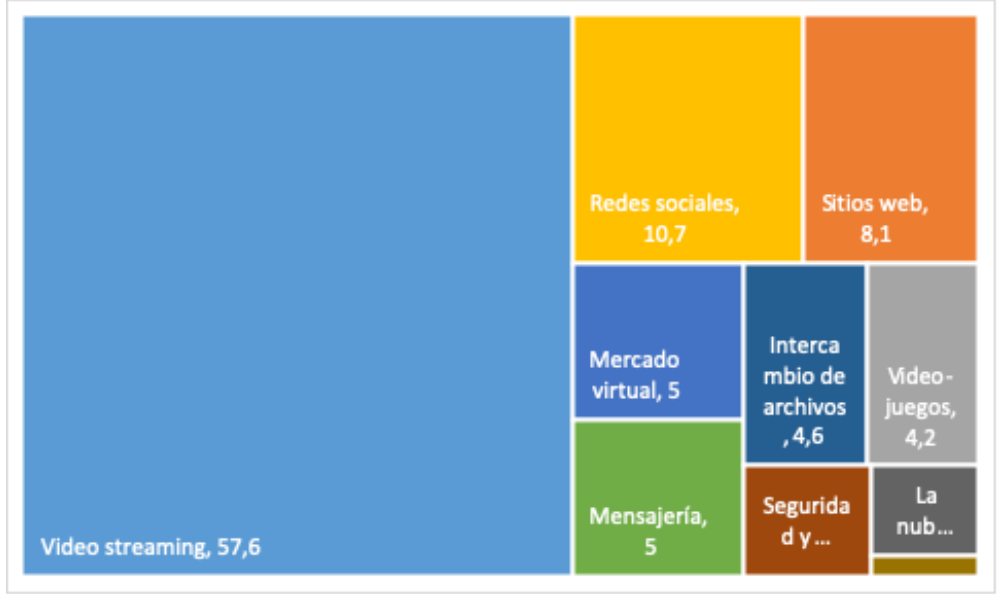

Gráfico 3. Cuota del tráfico en la red a nivel mundial, por actividades.

Fuente: Sandvine (2020).

El peso de las plataformas de streaming en el panorama audiovisual ya era importante en la era pre-pandemia y, por supuesto, la crisis sanitaria mundial ha provocado un importante incremento en su alcance y uso.

Sirva como ejemplo sintomático el buscador Google en España en el que crecieron de modo muy importante durante la crisis de la COVID-19 las consultas sobre precios, contratación y servicios ofertados por las distintas plataformas de streaming (Trescom, 2020). Destaca el número de cuestiones relativas a Netflix, pero también son muchas las preguntas sobre los otros grandes agentes del video bajo demanda a nivel mundial: HBO, Movistar, Amazon prime y Disney +. El record, indicado con la cota 100, se alcanza en la cuarta semana de marzo y de la mano de Netflix, el resto de las plataformas obtienen niveles más modestos. Como se aprecia en el gráfico, el máximo logrado en esas fechas baja en las semanas siguientes. 
Pandemia, consumo audiovisual y tendencias de futuro en comunicación

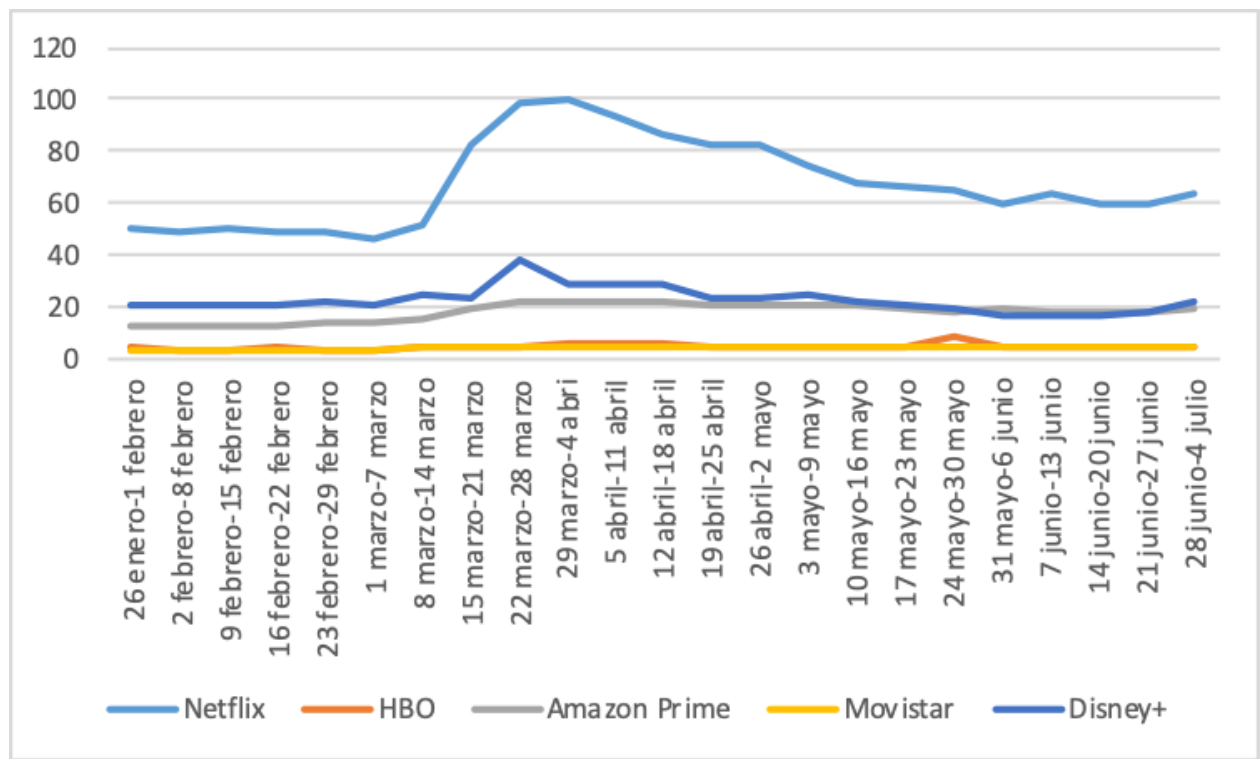

Gráfico 4. Evolución en España en el número de búsquedas en Google sobre plataformas de streaming.

Fuente: Trescom (2020).

Otro indicador de la innegable superioridad de Netflix es la cifra de nuevos suscriptores durante el confinamiento a nivel mundial, con 15,8 millones de nuevos clientes de pago entre enero y marzo, lo que supone 183 millones de suscripciones, un $23 \%$ más que el año pasado (Netflix, 2020). En el gráfico publicado por el portal Statista (2020b) se observa el impresionante crecimiento en el número de hogares subscritos a ésta OTT.

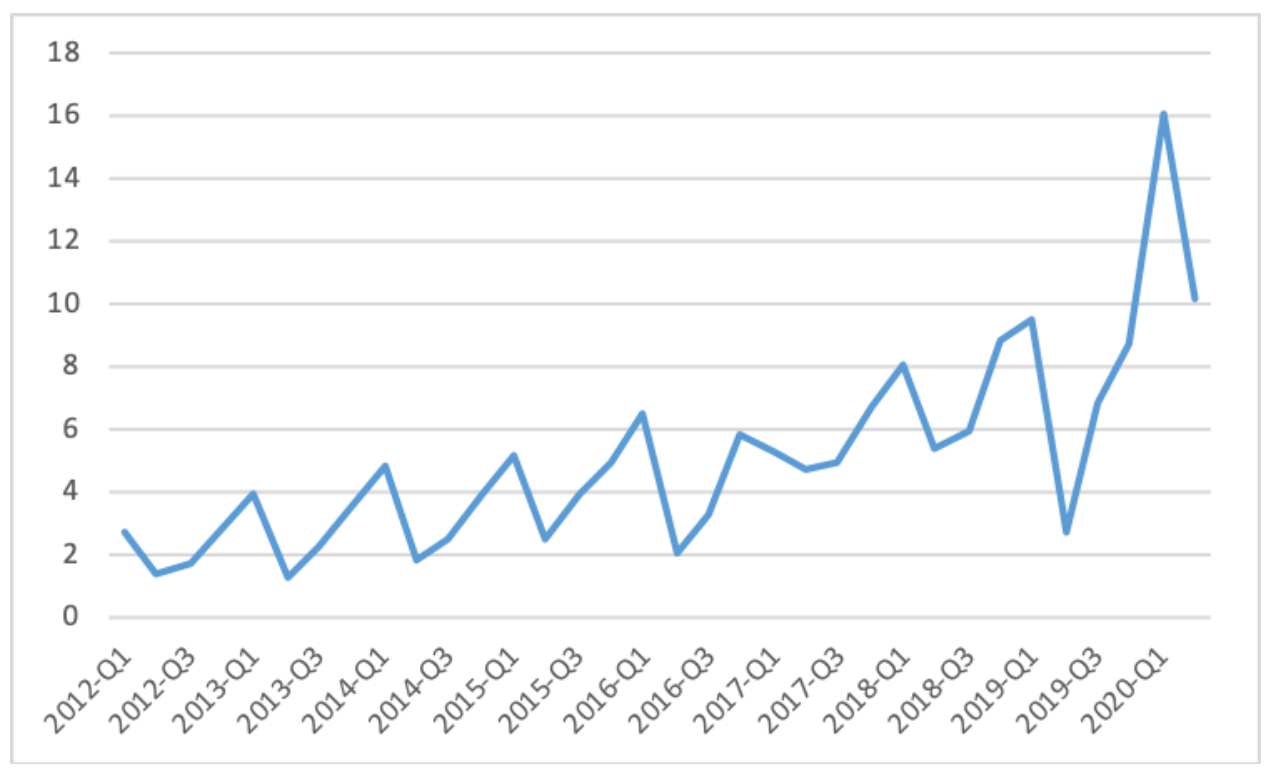

Gráfico 5. Evolución en el número de nuevas suscripciones a Netflix a nivel mundial. Fuente: Statista (2020b). 
De la mano de uno u otro operador, el fenómeno del visionado en streaming durante la cuarentena provocó cambios incluso en los horarios habituales en los que la población veía dichos contenidos (Conviva, 2020). Así, y aunque como es conocido la franja temporal por antonomasia de la televisión es el prime-time (comprendida entre la hora de cenar y la de acostarse, y que en el caso español cubre el periodo entre las 20:30 y las 24:00), crecieron mucho los productos en streaming consumidos fuera de ese horario histórico de máxima audiencia. Según la compañía de análisis Conviva, el incremento porcentual se dio principalmente entre las diez de la mañana y las cinco de la tarde, y el mayor aumento se registró entre las 11:00 y las 12:00 horas, un 43\%. Este cambio horario sin duda hay que entenderlo en el contexto del confinamiento domiciliario y de las nuevas maneras de gestionar el tiempo, pero debería servir también para hacer nuevas lecturas sobre el papel de los departamentos de programación televisiva y las técnicas que utilizan para atraer y mantener la audiencia (Arana, 2011; Ihlebaek, Syvertsen \& Ytreberg, 2013).

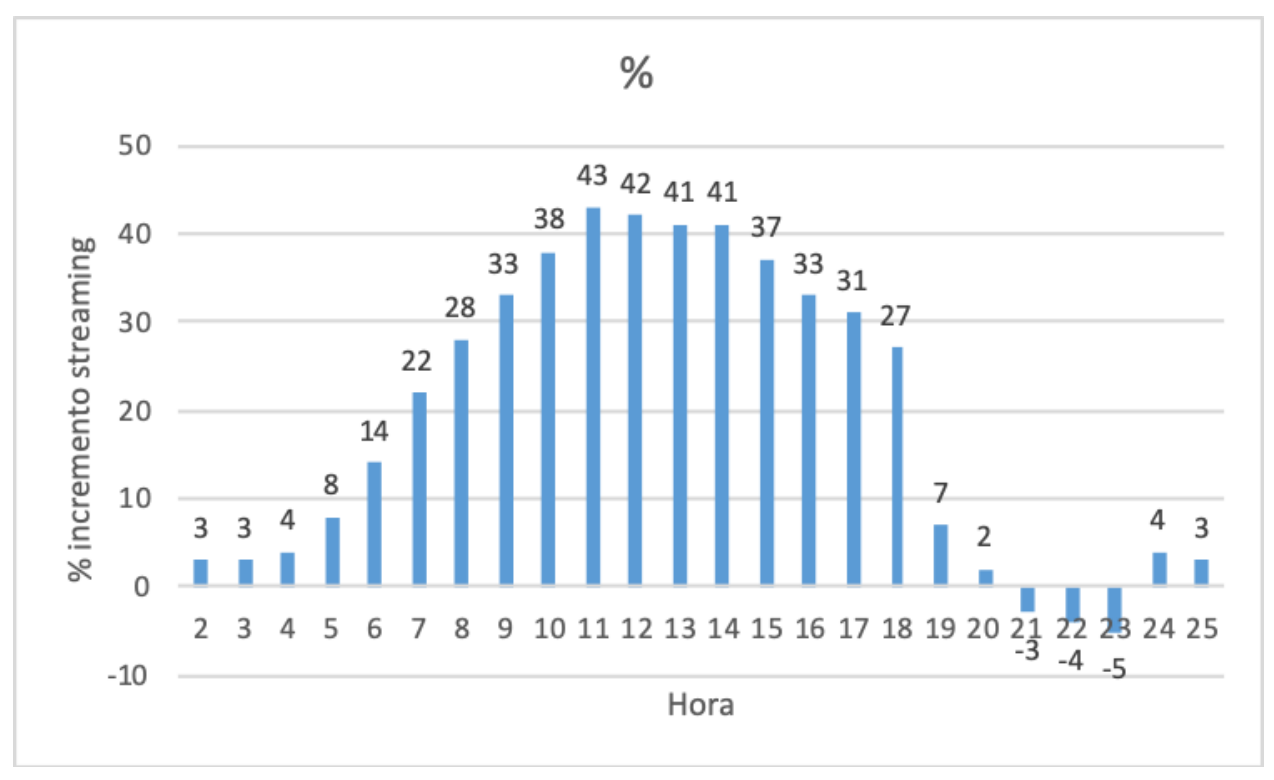

Gráfico 6. Evolución porcentual del consumo audiovisual en streaming, por horas del día, a nivel mundial.

Fuente: Conviva (2020).

Como se puede apreciar en el gráfico, aumentó el número de visitas a servidores de streaming realizadas en marzo de 2020 a plena luz del día y comenzando más temprano y el único decrecimiento se dio en las horas del prime-time de la televisión tradicional.

Tanto aumentó el consumo de plataformas de $V o D$ a raíz del confinamiento que empresas como Netflix, Amazon y Youtube se comprometieron a rebajar temporalmente "la intensidad de su señal a favor de la sostenibilidad de las redes fijas y móviles" (Lorenzo, 2020). 
Para concluir este subapartado en el que estamos analizando las tendencias a nivel global, nos referiremos brevemente el fenómeno del co-watching (termino inventado por Facebook aunque se ha extendido como etiqueta genérica para aplicaciones como Metastream o TwoSeven, que permiten compartir contenido en grupo). El confinamiento no solo ha disparado el consumo de contenidos audiovisuales, sino también la oferta y el uso de aplicaciones para ver dichos contenidos colectivamente (Sanz, J.L., 2020). A pesar de no estar físicamente en el mismo lugar, estas aplicaciones permiten "reunirse" a través de una misma pantalla compartida y vuelven a poner sobre la mesa la importancia de vivir experiencias en común, de la concurrencia de los usuarios aunque solo sea de manera virtual en un "lugar" y en un "momento". Este coincidircompartiendo ha proliferado durante el confinamiento más allá de la programación lineal de la televisión tradicional y se han puesto en boga plataformas que ofrecen la posibilidad también de auto-programar el visionado con los amigos o los miembros de la familia, creando playlists, es decir, consumo a la carta, pero visionando el mismo contenido desde distintos dispositivos. El ser humano se vuelve así a manifestar como un animal que busca la proximidad y rehúye la distancia social, también en su faceta de consumidor audiovisual.

\subsection{Algunas referencias de los consumos y actitudes sobre los medios en España durante el confinamiento}

Anteriormente ya hemos destacado que se puede hablar de una tendencia creciente al consumo de medios durante las semanas de duración del estado de alarma. Esto ha afectado no solo a la cobertura sino también al montante de horas de conexión a Internet y al uso de otros medios, principalmente de carácter audiovisual. En lo que sigue haremos un breve repaso a cómo ha afectado el confinamiento a los patrones de consumo de medios en España, basándonos en los datos facilitados por el Instituto IMOP (2020) y la AIMC-Asociación para la Investigación de Medios de Comunicación (2020).

Durante las distintas etapas que ha tenido la gestión de la crisis del coronavirus en la primera mitad del año 2020 (desde la declaración del estado de alarma y el confinamiento en España el 14 de marzo, pasando por las tres fases de la pandemia y, finalmente, el levantamiento de las restricciones de movimiento, la tercera semana de junio) el Instituto IMOP ha publicado hasta diez informes, entre otras cuestiones, analizando los cambios que se han producido en el consumo de medios.

En sintonía con los datos expuestos en los epígrafes previos, en España han medrado el consumo de medios, entre ellos los de carácter informativo, los basados en el lenguaje audiovisual y las TIC.

Así, por ejemplo, según el Instituto IMOP, el aumento en el consumo de medios se notó tanto en su penetración social como en el tiempo que se le dedicaba al día: la primera semana de confinamiento el número de personas que pasaban frente a la pantalla de TV cuatro o más horas creció alrededor del $46 \%$ y este porcentaje llegó al $81 \%$ en mayo. Del mismo modo, la radio, especialmente la de carácter informativo,

Revista de Comunicación y Salud, 2020, Vol. 10, no 2, pp. 149-183 
ganó en relevancia social. En cuanto al acceso a Internet, la diferencia fue también sustancial. Antes del confinamiento un $76 \%$ de la población accedía a la red a diario desde casa y un $46 \%$ cuando estaba fuera de ella. Los minutos dedicados a conectarse eran en ambos emplazamientos de más de dos horas y media cada día. Durante el confinamiento domiciliario, el porcentaje de gente conectada desde casa subió al 83\% de la población y a los 273 minutos diarios. Consecuentemente, el cambio fue a la baja en cuanto a los consumos fuera del hogar, que descendieron a un $10 \%$ de la población y la cantidad de tiempo se mantuvo en cotas similares (168 minutos al día).

La intensificación del consumo de medios y de los distintos recursos TIC se reflejó también en el tiempo dedicado a los video-juegos y la suscripción a servicios de $V o D$ Video-on-Demand. En el primero de los casos hay que destacar que el $44 \%$ de la población española entre 14-64 años ha jugado alguna vez a los video-juegos en lo que va de año 2020. Ese porcentaje, obviamente es muy superior en las franjas de edad entre los 14-34 años, superando el 60\%. La cantidad de tiempo invertida por los gamers también aumentó y si antes del coronavirus era de alrededor de 90 minutos al día por jugador, durante el confinamiento prácticamente se duplicó (179'). Si atendemos en particular a la gente de menos de 25 años, las cifras son todavía más abultadas y se pasó de los 110 minutos anteriores a los 233 diarios durante el estado de alarma.

Según los informes publicados por el Instituto IMOP, además, creció en España el porcentaje de personas suscritas a servicios de TV de pago (hasta un $45,3 \%$ de la población) y de servicio de video bajo demanda, llegando a un 56,9, principalmente de la mano de Netflix.

Atendiendo a los "Cuadernos de bitácora" publicados por la AIMC (2020), el confinamiento afectó al tiempo que la gente permanecía conectada y, también, a la compra de equipamiento tecnológico (Smart TV, tableta y ordenador portátil, etc.) que se incrementó en un $9,4 \%$.

Para terminar, destacaremos que, según los encuestados durante el estado de alarma, y aunque el 93,7\% valoraban positivamente el papel de los medios, a la hora de recibir información contrastada y fiable, también "comienza a producirse cierta saturación de información sobre la situación actual" y en consecuencia aumentan los consumos de carácter lúdico y con el objetivo de entretener. (AIMC, 2020)

\subsection{El cuándo, cómo y qué de los consumos digitales entre los jóvenes universitarios vascos}

En los párrafos previos hemos subrayado los cambios globales que se han producido en el consumo de medios y, más en detalle, el canalizado a través de los medios online e Internet. Como hemos señalado, se aprecia una mayor penetración e importancia en cuanto a tiempo que acaparan por parte de la población general. Ahora nos referiremos a un grupo muy concreto, compuesto por jóvenes universitarios de entre 18-23 años, en el convencimiento de que sus pautas de consumo nos pueden servir para esbozar algunas tendencias que podrían generalizarse en un futuro próximo al resto de la 
población (sobre los trendsetters, puede consultarse Ramos \& Pac, 2019). Porque todo parece indicar que algunas de las pautas de consumo y actitudes para con los medios que habitualmente se atribuían a los públicos más jóvenes, durante el confinamiento se han extendido a otros segmentos etarios, casi con la misma velocidad que lo hacían las infecciones por el virus. En los informativos televisivos hemos visto vídeos subidos a Youtube en los que los trabajadores de los hospitales aparecen explicando sus experiencias, llamando a la precaución o cantando como muestra de unión y solidaridad; se ha popularizado el uso de video-llamadas en las residencias de ancianos; ha crecido enormemente la suscripción al pago de los servicios OTT; en pocas palabras: se ha hecho imprescindible estar conectado. También aquellos públicos más reticentes, por edad, tradición en el uso de las TIC o cualquier otra razón, se han convertido durante el estado de alarma, y casi sin querer, en expertos en software para video-llamadas o en usuarios de redes sociales. El mes de marzo provocó un incremento en la socialización de las nuevas tecnologías y la normalización de muchas prácticas culturales relacionadas con los contenidos audiovisuales que hasta entonces afloraban casi exclusivamente entre la gente joven. $Y$ todo parece indicar que estos cambios no tienen vuelta atrás y que la lucha en el terreno mediático y cultural a partir de ahora se jugará sobre todo en el ámbito digital. Por eso, en lo que sigue analizaremos las tendencias que aparecen entre aquellos públicos más jóvenes, más abiertos a nuevas pautas de consumo y para los que lo tecnológico es puramente instrumental, aquellos públicos más pioneros.

Para ello, como ya hemos indicado, utilizaremos los datos resultantes de una investigación basada en el panel estable compuesto por más de setecientos estudiantes de la Universidad del País Vasco/Euskal Herriko Unibertsitatea, pertenecientes a veinte grados universitarios diferentes, de los tres campus de la UPV/EHU y provenientes del País Vasco y de otras áreas cercanas. De este modo conoceremos cómo son los consumos audiovisuales de los y las jóvenes universitarios, en un momento de la historia en el que el coronavirus convirtió el día a día en un escenario de confinamiento generalizado (Narbaiza, 2020).

Preguntados por sus patrones de consumo, los alumnos han sido categóricos en sus respuestas: durante el confinamiento han aumentado sustancialmente su uso de las tecnologías de la información y la comunicación e incrementado el tiempo dedicado a los contenidos audiovisuales, tal y como se aprecia en los gráficos que siguen. 


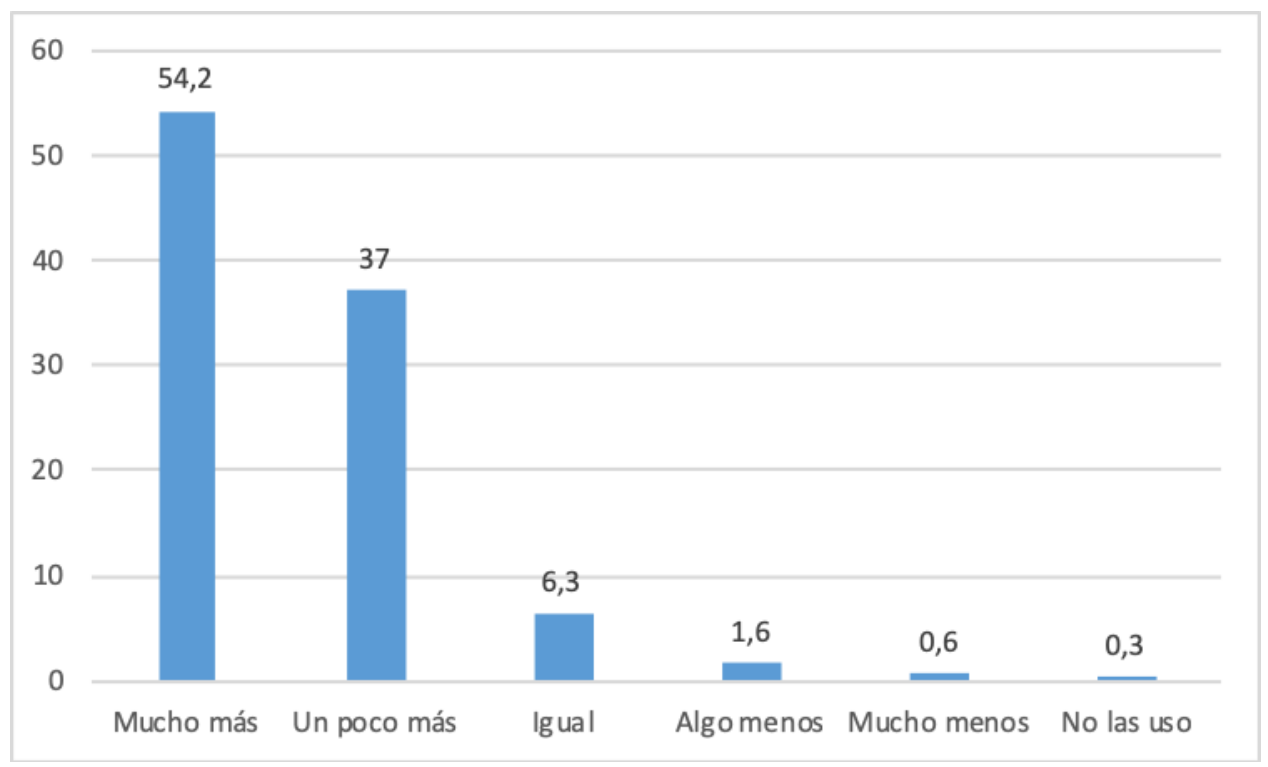

Gráfico 7. Evolución en el nivel de consumo audiovisual y uso de las TIC durante el confinamiento en relación a periodos anteriores.

Fuente: Ikusiker (abril de 2020).

Sólo un $8,8 \%$ de los panelistas consumen igual o menos que antes de la cuarentena, la gran mayoría lo hace mucho más $(54,2 \%)$ o un poco más $(37 \%)$ que antes de entrar en el confinamiento. Lo que hace un total de $91,2 \%$ de valores al alza.

En el gráfico número 8 ahondaremos un poco más en el citado incremento del consumo con el objetivo de saber en qué medios o soportes concretos invierten su tiempo los universitarios del panel. A primera vista, se aprecia que entre las y los jóvenes algunos medios y soportes cuentan con más adeptos (y más intensivos en sus usos). En todo caso, sería un error no prestar atención a aquellos que tienen menos usuarios. Es necesario pues hacer una lectura detallada y, por ejemplo, fijarse en aquellos medios aparentemente menos exitosos, pero que han conocido un importante incremento durante el confinamiento. Sirvan como ejemplo los canales de televisión de pago que todavía hoy puede que no acumulen grandes cifras, aunque eso sí, son sustancialmente mayores que hace muy poco tiempo. El caso de la tele de pago manifiesta una subida del cero al $23 \%$ en un plazo muy corto y viene a ilustrar el cambiante panorama mediático y, en este caso, el inusitado interés por estos servicios de gigantes multimedia como Atresmedia o Movistar.

En dicho gráfico se recoge también la cantidad de tiempo que los jóvenes dedican cada día a los consumos en diferentes plataformas y soportes. Las respuestas evidencian la ruptura con la linealidad de los medios audiovisuales tradicionales, y nos referimos en particular a la televisión. La cantidad de dispositivos que utilizan los jóvenes les permiten además consumos simultáneos en más de un soporte y esta opción se aprovecha sin complejos para sincronizar, por ejemplo, redes sociales y VoD. Las redes sociales, sean Instagram, Twitter, Facebook o Youtube son claros ejemplos de los consumos paralelos al estar permanentemente activadas en las manos de los 
jóvenes universitarios mientras consumen otros contenidos audiovisuales y/o como herramienta de interacción, en muchos casos sobre esos mismos contenidos.

Antes de adentrarnos en una lectura más precisa, dos apuntes sobre la fidelidad a los distintos soportes y contenidos. No cabe duda de que las modas, las tendencias audiovisuales entre los amigos y compañeros, se convierten en alguna medida en "obligaciones sociales" que propician el visionado de uno u otro contenido. En esto no parece que haya grandes diferencias a periodos anteriores. Pero si las hay en la cuantía de dicha "obligatoriedad". El resultado es que aquellos agentes con capacidad de provocar tendencia son, en parte, los que crecen de manera fulminante. Dicho eso, no hay duda de que en el actual panorama audiovisual conviven tipologías de contenido muy diversas, aquellas de altísima calidad y presupuestos millonarios con los de carácter indiscutiblemente amateur; y pese a lo que pueda parecer los usuarios no los viven como auto-excluyentes, sino como piezas del mismo zoco audiovisual al que pueden concurrir: plataformas de pago y gratuitas; locales y globales; en inglés, francés, euskera o alemán. Contenidos todos ellos de muy diversos formatos y procedencias que confluyen en un mismo terreno de juego: Internet. $Y$ en ese amplio entorno virtual se entremezclan los videos y programas recomendados por amigos, programados por canales de televisión tradicional y en muchos casos propuestos al usuario en base a algoritmos. Contenido que al estar accesible y en el entorno digital es parte del gran catálogo audiovisual contemporáneo (Prado, 2009).

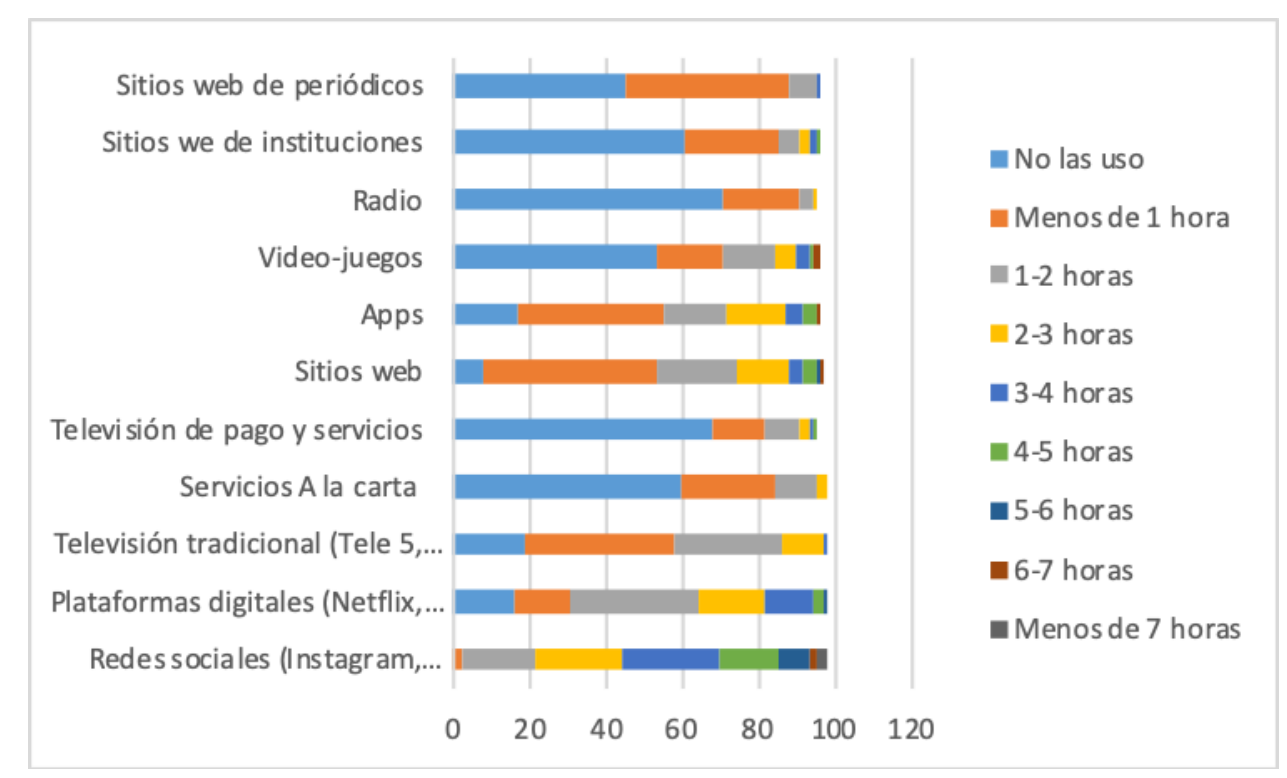

Gráfico 8. Tiempo dedicado por los jóvenes universitarios del País Vasco a cada medio o plataforma durante el confinamiento.

Fuente: Ikusiker (abril de 2020).

En este gráfico, se aprecia el papel preponderante que tienen las redes sociales, tanto por la penetración en este público joven como por el tiempo que acaparan, ya que la mayoría del panel (61\%) se sitúa en un consumo de entre dos y cinco horas diarias. Sirva como contraste que el número de personas que no las utilizan es de solo un 
$0,4 \%$. Youtube e Instagram son las plataformas preferidas, pero otras han entrado con mucha fuerza, como la china TikTok (ni siquiera aparecía citada en una encuesta hechas entre los panelistas en 2019).

El coronavirus ha acelerado procesos que ya se venían dando anteriormente de modo más lento, y así la tendencia mundial al aumento en las suscripciones a servicios de OTT de pago se ha extendido, como ya hemos apuntado antes. Los y las alumnas de la UPV/EHU no son una excepción. Hace seis meses, sólo la mitad tenía acceso a este tipo de servicios, en pleno COVID-19 las cifras indican que ahora más del $85 \%$ utiliza estos proveedores de pago. Por si fuera poco, hay que apuntar que en alguna medida se rompe el monopolio de facto del que hasta entonces disfrutaba Netflix y se concreta una tendencia a tener más de un servicio de pago. Aunque Netflix sigue siendo el dominante (82\%), otros proveedores como Amazon Prime Video y HBO ganan peso entre los universitarios. Además, y para terminar, algunas plataformas de televisión de pago del Estado español son muy tenidas en cuenta, especialmente las ofertadas por Movistar que alcanzan entre los jóvenes un 7\%, pero también resulta avalada por el público joven la estrategia de canales de pago desarrollada por Atresmedia.

En cuanto al consumo de televisión tradicional, durante los días de confinamiento el visionado aumentó considerablemente, incluso entre los jóvenes: en noviembre de 2019 eran más del $50 \%$ los que declaraban no ver la televisión, una cifra que se reduce considerablemente en el periodo de cuarentena (23\%). En el mismo sentido hay que analizar el incremento de las visitas a los sitios web de los periódicos, donde la mitad de los jóvenes $(50,4 \%)$ entra alguna vez. Aunque en estos sitios web pasan menos tiempo que en otras plataformas, las páginas web de las televisiones y de los periódicos son consideradas fuentes fiables de información, como se ve a continuación.

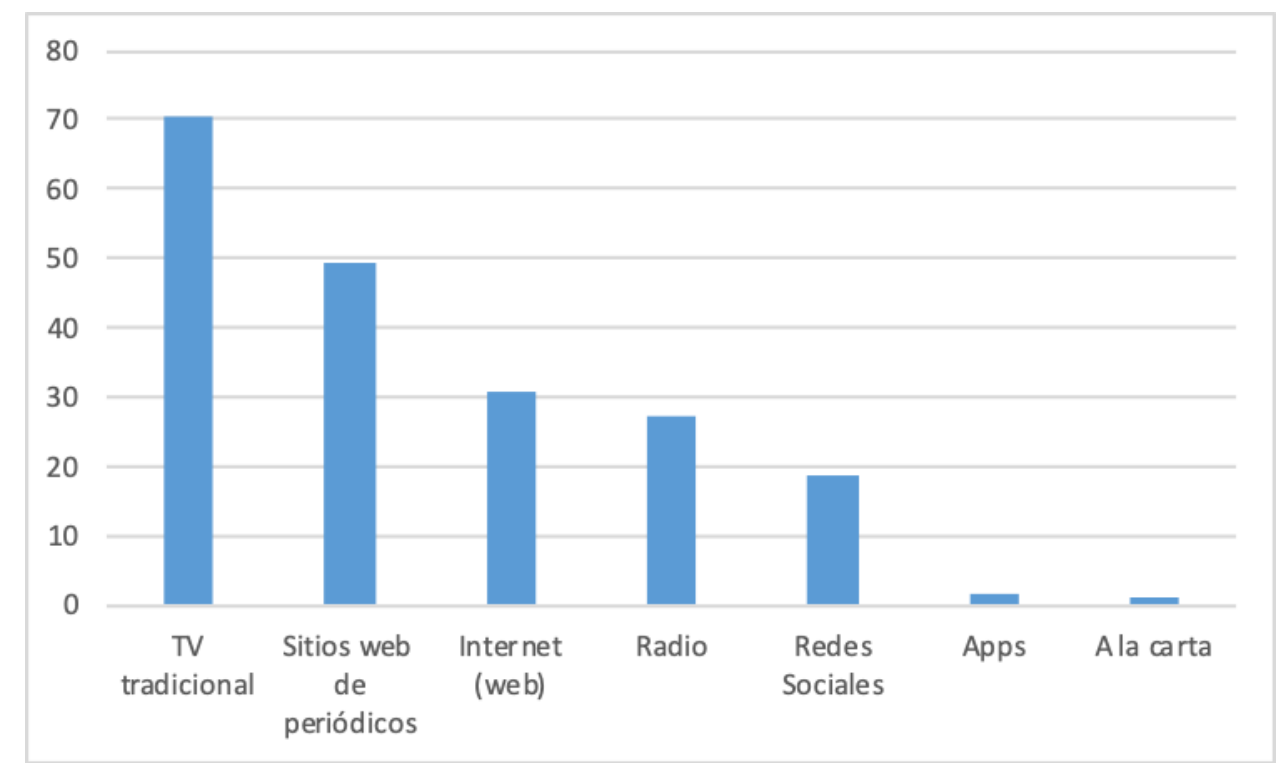

Gráfico 9. Fiabilidad atribuida a las distintos medios de comunicacion como fuentes de información sobre el coronavirus.

Fuente: Ikusiker (abril de 2020). 
Al ser preguntados pues por las fuentes de información que consideran más fidedignas, los universitarios del panel destacan la televisión tradicional (71\%). Entre los canales concretos que merecen su confianza, en la parte alta del ranking aparecen canales públicos (ETB2, TVE1 y ETB1). A esta lista de televisiones consideradas fiables le siguen las webs de los periódicos (50\%). A continuación aparecen las webs generales de Internet y las radios, que obtienen resultados similares entre los jóvenes panelistas, ambas en torno al $30 \%$. A pesar de señalar que las redes sociales son las fuentes de información que menos confianza les suscitan (19\%), en comparación con otras opciones, reconocen que reciben la mayor parte de la información sobre la COVID 19 a través de dichas redes sociales.

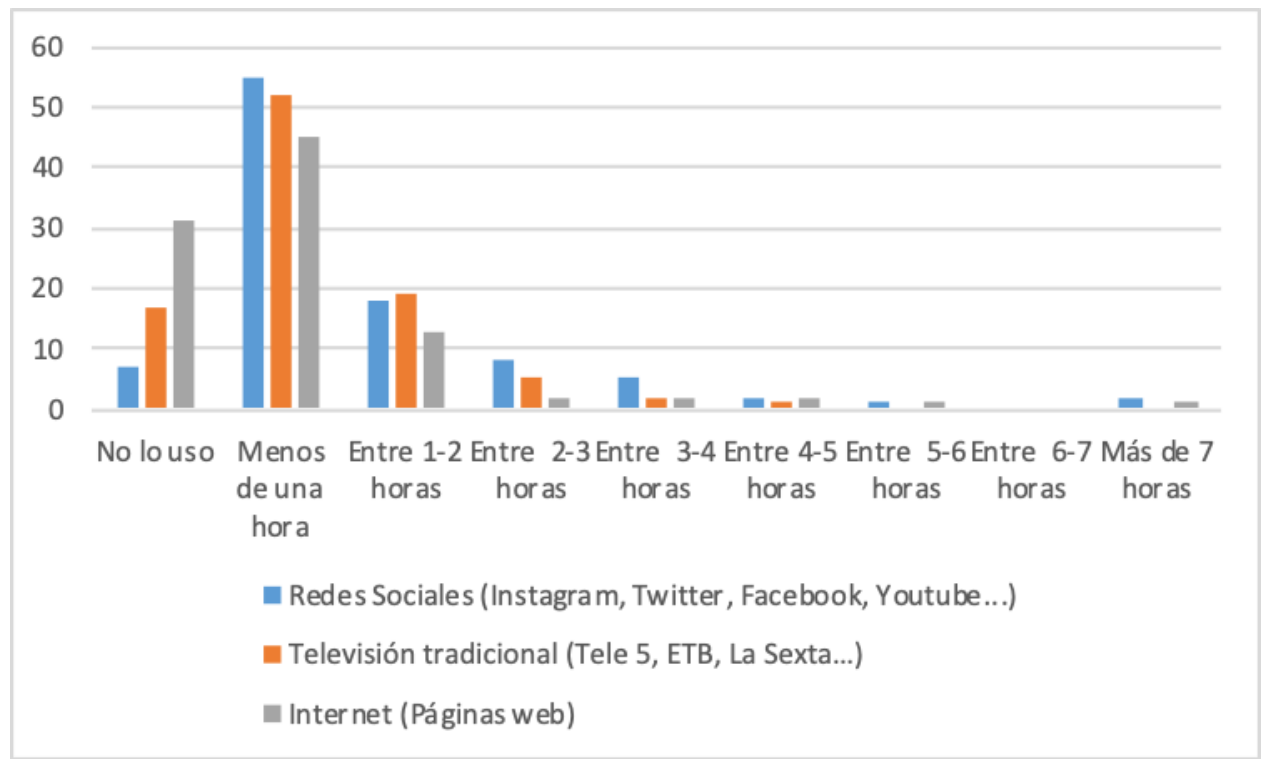

Gráfico 10. Tiempo dedicado a las distintas fuentes de información sobre el coronavirus.

Fuente: Ikusiker (abril de 2020).

El tráfico de información canalizado a través de las redes sociales es enorme y muy variados los agentes que participan en el mismo. Las redes ofrecen la posibilidad de recibir información que nunca se hubiera podido obtener de otro modo, pero también a menudo sin el necesario control sobre los mensajes que han llegado a través de las distintas redes y que han sido consumidos a medida que llegaban (en el punto 4.1 nos hemos referido a la infodemia). En cualquier caso, se observa que los jóvenes siguen con interés la información sobre el coronavirus, ya que la mayoría le hacen un hueco importante en su día a día. Y utilizan todos y cada uno de los medios y recursos a su alcance, sin excluir ninguno. 


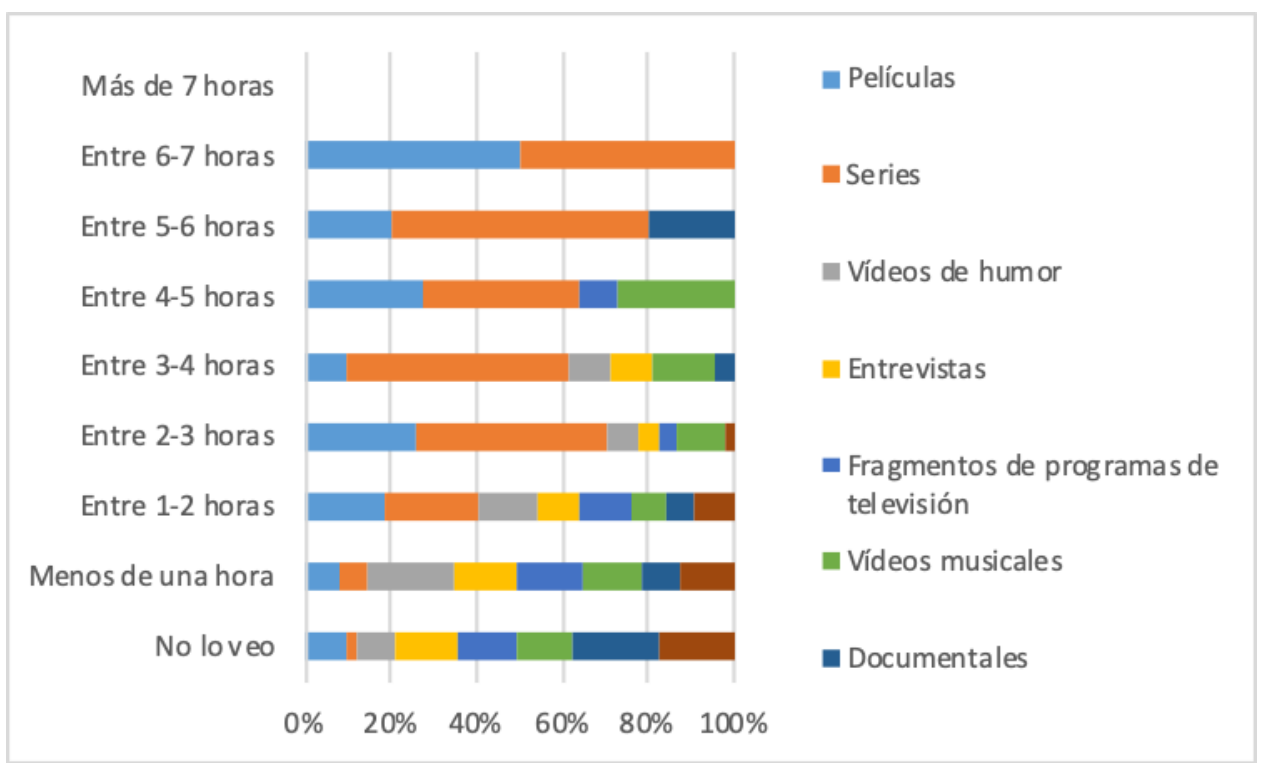

Gráfico 11. Tiempo dedicado a los distintos contenidos de entretenimiento.

Fuente: Ikusiker (abril de 2020).

El consumo de productos audiovisuales de entretenimiento es enorme. Como se puede apreciar en el gráfico número 11, aunque existen diferencias entre los contenidos concretos elegidos por los jóvenes panelistas, el dato global es muy significativo y nos da una muestra del peso que adquiere en su conjunto. La integración de este tipo de consumos y su dedicación horaria ha tenido sin duda gran repercusión en el modo en el que los panelistas han organizado su jornada diaria. Queda por ver si estas tendencias se mantendrán y provocarán cambios coyunturales en el modo de utilizar el tiempo por parte de los jóvenes universitarios.

Si nos adentramos en el género de los contenidos más vistos, cabe destacar la ficción y dentro de ella las series. La mayoría de los más de 700 alumnos que conforman el panel reconoce ver series $(89 \%)$. Y un porcentaje importante películas (77\%). Si ya desde hace tiempo la mayoría de los contenidos de entretenimiento se consumían online, el confinamiento no ha hecho más que acentuar esta tendencia. "Cuando se quiera, y tanto como se desee" podría ser otra de las máximas derivadas de los cuestionarios que hemos dirigido a los jóvenes del panel lkusiker, aunque también parece detectarse algo de empacho en cuanto a ciertos consumos.

Por otra parte, lo señalábamos antes, durante el encierro, las tecnologías han sido aliadas en el objetivo de romper el aislamiento que ha supuesto el confinamiento en casa y todos, jóvenes y mayores, han querido encontrar el modo más adecuado para mantenerse comunicados. Así, merece destacar la cantidad de tiempo que los panelistas han pasado relacionándose con amigos y familiares. Entre los alumnos, un $23 \%$ reconoce una inversión de entre 2 y 3 horas al día y un $22 \%$ entre una y dos horas, pero además son muchos los que le han dedicado más de tres horas a ese quehacer (43\%). 


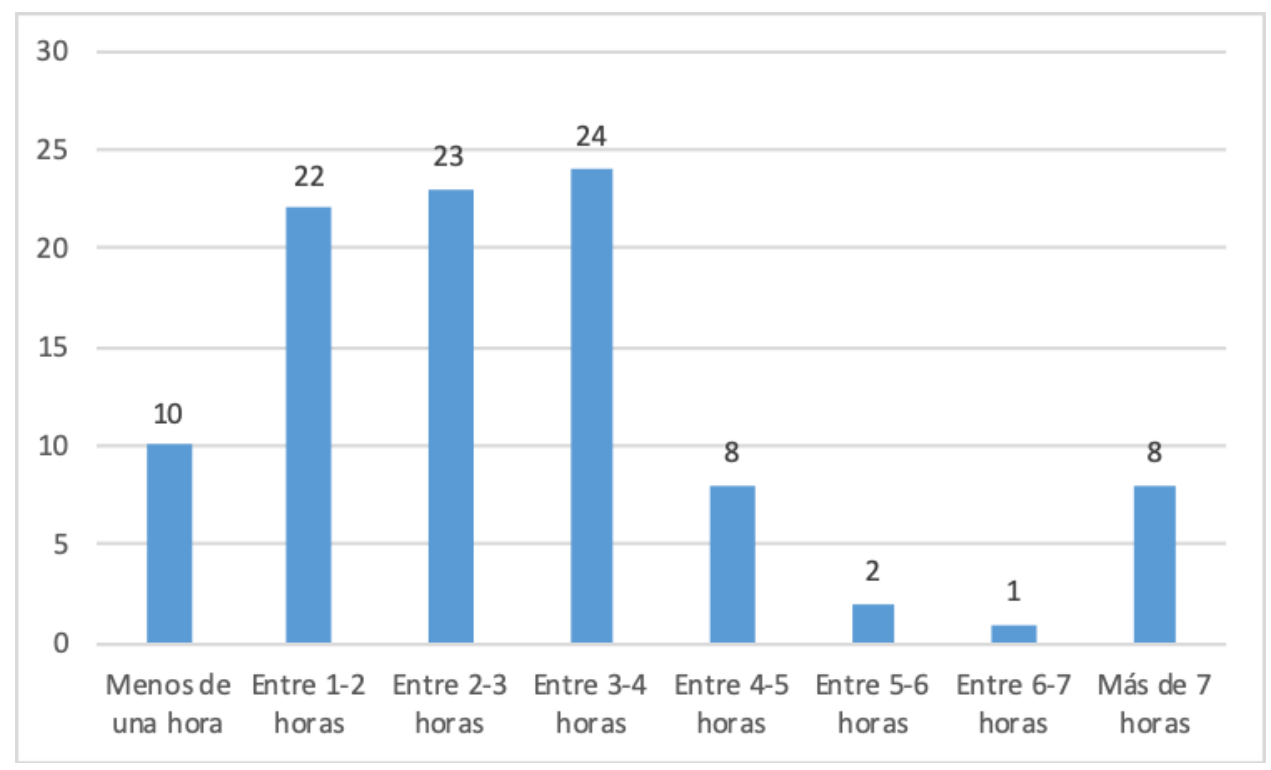

Gráfico 12. Tiempo dedicado a chatear, hablar por teléfono, las redes sociales o compartir videos.

Fuente: Ikusiker (abril de 2020).

En resumen, en un contexto en el que ya el uso de las tecnologías de la información y la comunicación y el consumo audiovisual eran enormes, la cuarentena causada por la COVID-19 establece las condiciones idóneas para aumentar y ampliar dichas prácticas.

Para terminar este repaso a los distintos aspectos de la comunicación que han notado cambios durante y a raíz del confinamiento, queremos subrayar las razones por las que los y las estudiantes universitarios recurren a las redes sociales. Destacan entre estos motivos cuatro: estar en contacto con familiares y amigos, mantenerse informados sobre la actualidad, pasar el rato y, probablemente por esta última razón, ver cosas divertidas y graciosas.

Instagram Facebook o Twitter son recursos que los universitarios utilizan reiteradamente y así un $82 \%$ lo usa siempre o casi siempre para estar en comunicación con su gente conocida. Sus amigos están en las redes sociales (siempre o casi siempre en un $54 \%$ de las respuestas). Pero, además, este contacto se concreta también en el deseo de estar informados sobre las noticias de relevancia. Un 53 por ciento de los panelistas destacan ese motivo para conectarse siempre o casi siempre a las redes sociales y alguna vez otro $33 \%$. "Pasar el rato" y "ver cosas divertidas" son otras dos razones muy recurrentes. Un $47 \%$ y otro $41 \%$ de los panelistas explicitan esos porqués para unirse a las redes "bastantes veces" o "siempre" (a los que se podría añadir otros $17 \%$ y $36 \%$ que lo hacen "alguna vez"). 


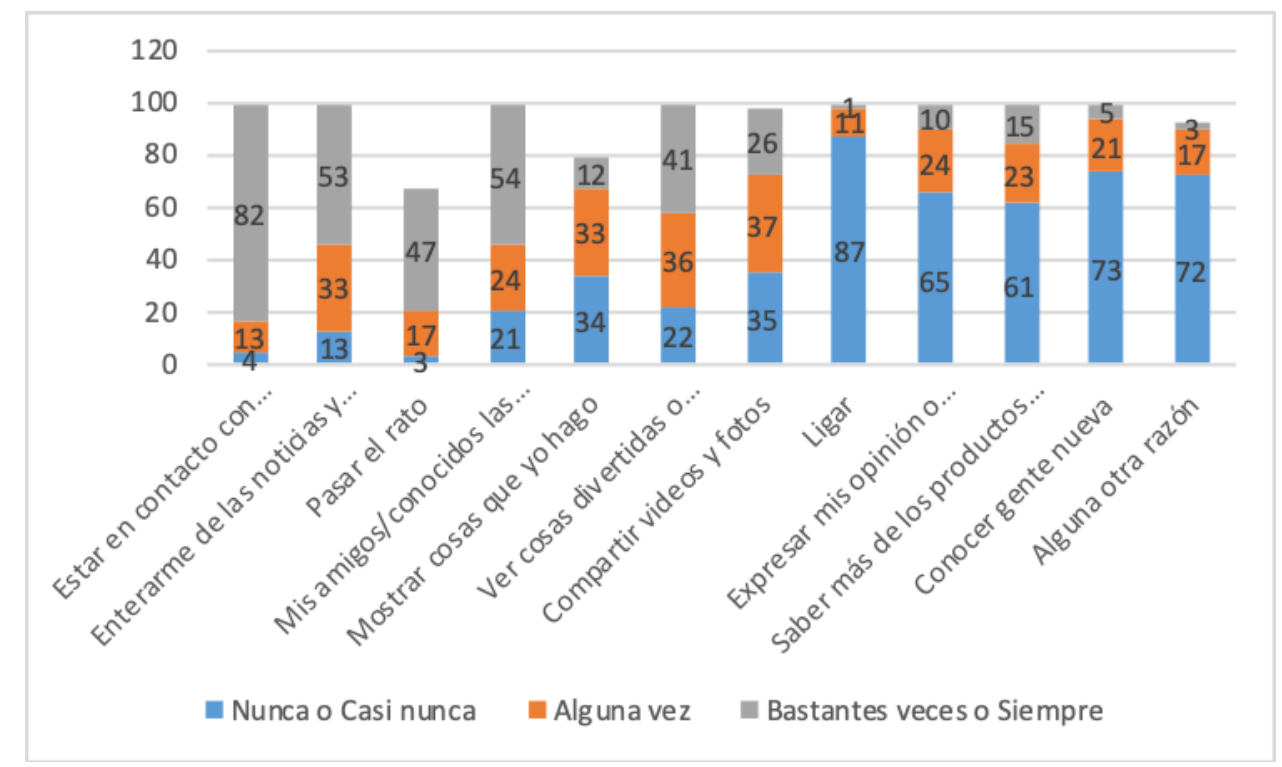

Gráfico 13. Motivos por los que utilizan las redes sociales.

Fuente: Ikusiker (abril de 2020).

En lo que va de artículo, hemos hecho un triple recorrido que va desde el análisis de la situación en ámbitos geográficos y mediáticos muy amplios a aquellos más próximos; también nos hemos referido a segmentos sociales generales primero y luego a los miembros de un panel de estudiantes universitarios; y con todo, aunque nos hayamos centrado en las semanas del confinamiento, también hemos citado situaciones previas para tratar de apuntalar los elementos clave del momento actual. Todo ello en el convencimiento de que, en alguna medida, en las presentes circunstancias se están poniendo las bases de lo que pueden ser los modos y las actitudes sobre comunicación que ya están llamando a la puerta.

\section{RECOPILANDO INDICIOS}

El Coronavirus sacudió la primavera de 2020 y obligó a los distintos agentes a reposicionarse en el nuevo tablero de juego político, económicos, social y mediático.

Es difícil saber si las tendencias en el panorama de la comunicación que se han manifestado en esta etapa inicial se mantendrán en el futuro, en un momento histórico ya dominado por la globalización, la digitalización y la convergencia de medios. Sin embargo, y aun siendo conscientes de que el día a día traerá más cambios y nuevas incertidumbres, todo apunta a que algunas de los aspectos emergentes que se han manifestado en esta fase de la crisis de la COVID-19 se asentarán y perdurarán en el tiempo. El Key Trends 2019-2020 Report (European Audiovisual Observatory, 2020) publicado recientemente confirma la tónica ascendente en los consumos audiovisuales online, en relación a los previos a la crisis del coronavirus. Aumentan las subscripciones a servicios de VoD en Europa, entre otras zonas del mundo y crece el número de usuarios y de tiempo de visionado de Youtube. 
Pandemia, consumo audiovisual y tendencias de futuro en comunicación

¿Qué pasará al relajarse las medidas de distanciamiento social? A pesar de que las cuarentenas estrictas van mutando poco a poco en una nueva normalidad, todo apunta a que en los próximos meses seguiremos pasando más tiempo en casa que antes de la pandemia. Por tanto, la Connected TV, las suscripciones a OTT y, en general, todo tipo de opciones de ocio online en el hogar, y en cualquier dispositivo, continuarán viviendo su edad de oro. (Labelium, 2020)

Como se ha señalado en los distintos subapartados de este artículo, durante el encierro se ha generalizado la tendencia hacia la hiperconexión, y en eso coincidieron países en otras cuestiones tan lejanos como Italia, Corea del Norte, China, Noruega, Nueva Zelanda o muchos latinoamericanos. La navegación en la red ha respondido así a varias necesidades: la búsqueda de noticias que ayudaran a entender lo que estaba pasando, contrarrestar virtualmente la obligada distancia social y gestionar de otro modo el tiempo. En el primero de los casos, eso ha provocado que la ciudadanía recurriera a más fuentes de información y las usara durante más tiempo. En el segundo, que tanto jóvenes como mayores conocieran o utilizaran más prolijamente sistemas de comunicación y, entre ellos, videoconferencias, para afrontar el aislamiento al que la pandemia inexorablemente les empujaba. Pero, además, muchos ciudadanos que han vivido el aislamiento domiciliario solos o en familia, han comenzado a crear nuevas rutinas para reorganizar su día a día, aprovechando para ello todos los dispositivos online a su alcance y en muchos de los casos buscando el entretenimiento.

Ya se han desgajado algunas de las cuestiones apuntadas en la parte inicial de este escrito en lo que tiene que ver con las tendencias comunicativas que han manifestado a nivel mundial y si se han dado de modo similar en los distintos contextos sociales y mediáticos. En lo que sigue se incluyen además algunas reflexiones relacionadas con el nuevo marco de la comunicación, los roles que los distintos medios y plataformas asumen y las nuevas pautas de consumo mediático.

- Las innovaciones tecnológicas, las de la industria de la informática y las telecomunicaciones se han combinado ya perfectamente con las de los medios de comunicación, creando un nuevo escenario a nivel mundial. La crisis del coronavirus no ha hecho en muchos casos más que acelerar algunos procesos, porque muchos venían desde hace cuando menos dos décadas y, lo que es más importante, faciliar que se incrustara en todo el tejido social y a través de nuevos hábitos de consumo de medios de las TIC.

- En este panorama general tiene mucha importancia la forma en que la población materializa la comunicación, por qué elige unos u otros soportes tecnológicos y en qué medida estos satisfacen sus deseos y necesidades. La apropiación social de la tecnología y sus dispositivos seguirán siendo cuestiones de mucha importancia.

- Hasta principios del nuevo siglo, cada medio de comunicación contaba con un soporte propio y prácticamente exclusivo (el papel para los periódicos y las revistas, las ondas para la radio y televisión) ahora sin embargo los medios son multiplataforma y los contenidos fluyen por todos ellos (Jenkins, 2008; Scolari, 2013). Conscientes de esta versatilidad, las corporaciones trabajan dichos contenidos desplegándolos, sobre todo, a través de soportes digitales que

Revista de Comunicación y Salud, 2020, Vol. 10, no 2, pp. 149-183 
Pandemia, consumo audiovisual y tendencias de futuro en comunicación

permiten consumos en cualquier momento, lugar y utilizando diferentes dispositivos. La interactividad está también en la base de los medios digitales.

- Las grandes tendencias en comunicación, en lo que respecta a la producción, distribución y consumo, se orientan hacia lo más global y todo indica que prevalecerán sobre las peculiaridades locales. Es este un aspecto que hay que seguir estudiando con atención, pero la avalancha mundializadora es indudable y puede causar consecuencias muy serias en mercados mediáticos de pequeño 0 mediano tamaño, con industrias no asentadas o en contextos sociopolíticos y culturales de menor nivel económico. Las implicaciones de una globalización desbocada podrían tener consecuencias devastadoras también para la pluralidad informativa si no se diseñan políticas de comunicación desde la visión del servicio público (Prado, 2017; Zallo, 2016).

- Estamos ya inmersos en la era digital y la crisis sanitaria lo ha dejado más claro que nunca. La transformación digitalizadora ya no es una opción más, sino un requisito. $\mathrm{Y}$ afecta tanto a la estructura de medios como a los modelos de negocio, la creación y producción de contenidos, su distribución y el modo en el que la audiencia accede e interactúa con ellos. La premisa es ya: digital first (Salaverria, 2019).

- El contenido (re)conquista su centralidad y debe satisfacer los gustos, deseos y necesidades de la audiencia. Es, junto con la accesibilidad, un elemento clave que guía todo el proceso y que debe permitir que el usuario lo disfrute desde cualquier aparato y en el momento elegido. Si no fuera así, los contenidos podrían perderse en un catálogo sin límites en cuanto a temática o formato y sin claves de localización.

- La crisis del coronavirus ha provocado en la población un crecimiento inusitado en su consumo de medios. Una de las primeras consecuencias ha sido el aumento en el tiempo dedicado a la información, pero los distintos informes revelan también sustanciales diferencias por segmentos demográficos: los jóvenes optan primordialmente por los medios de comunicación online (y las redes sociales) como primera fuente de información, mientras que los más mayores se mantienen en la televisión tradicional. En cualquier caso, y de modo general, la pandemia ha puesto de manifiesto que se está produciendo un salto estructural hacia el consumo de lo digital, y que en ese camino los jóvenes llevan tiempo siendo la avanzadilla (Kantar Media, 2020; Barlovento, 2020).

- Entre los lenguajes de comunicación, el de componente audiovisual gana en importancia. Lo audiovisual para recibir información, para el intercambio de contenidos e incluso para la comunicación interpersonal.

En el ámbito de la comunicación pocas veces se repiten las mismas circunstancias y el escenario actual es además muy cambiante. Hablar de "vuelta a la normalidad" no parece tener mucho sentido cuando ya son otras las reglas de juego, los enfoques y los equilibrios entre los distintos agentes del actual ecosistema mediático. La puerta a las novedades sigue pues tan abierta ahora como en la primavera del 2020. 
Pandemia, consumo audiovisual y tendencias de futuro en comunicación

\section{REFERENCIAS}

AIMC (2020). Cuaderno de bitácora. Estudio de medios en la España confinada. AIMC. Recuperado de https://labur.eus/7x5vo

Arana, E. (2011). Estrategias de programación televisiva. Madrid: Síntesis.

Arango-Forero, G. (2013). Fragmentación de audiencias juveniles en un ambiente comunicativo multimedial: el caso colombiano. OBS, 7(4), 91-11.

Astigarraga, I. (2017). Gazteen interakzioa ikus-entzunezko edukiekin: Mondragon Unibertsitateko ikasleen kasua. (Tesis doctoral). Mondragon Unibertsitatea, Aretxabaleta.

Barkhuus, L. (2009). Television on the internet: new practices, new viewers. CHI-2009, April 4-9, 2479-2488. doi: 10.1145/1520340.1520351

Barlovento Comunicación (2020). Cambios de hábitos y preferencias de la ciudadanía española frente al televisor por la crisis del coronavirus. Barlovento Comunicación. Recuperado de https://labur.eus/AisAQ

Bedingfield, W. (2020). Coronavirus news fatigue is real and it could become a big problem. Wired. Recuperado de https://labur.eus/JVJXW

Benton, J. (2020). The coronavirus traffic bump to news sites is pretty much over already. NiemanLab. Recuperado de https://labur.eus/N46Tz

Berkeley News (2020). COVID-19 and the media: The role of journalism in a global pandemic. Berkeley News. Recuperado de https://labur.eus/yGD5y

Bondad-Brown, B. (2011). Examining traditional television and on-line video use in the new media environment: understanding the role of audience activity, media orientation, generational cohort, and contextual age (Tesis doctoral). University of California, Santa Barbara.

Bustamante, E. (Coord.) (2003). Hacia un nuevos sistema mundial de comunicación: Industrias culturales en la era digital. Barcelona: Fundación alternativas y Gedisa.

Campos, R., Pereira, I., \& Simöes, J.A. (2016). Activismo digital em Portugal: um estudo exploratório. Sociologia, Problemas e Prácticas, 82, 1-13. Recuperado de http://spp.revues.org/2460.

Castells, M. (2009). Comunicación y poder. Madrid: Alianza Editorial.

Conviva (2020). Streaming in the Time of Coronavirus: Conviva's COVID-19 Social \& Streaming Report. Conviva. Recuperado de https://labur.eus/M19ms 
Pandemia, consumo audiovisual y tendencias de futuro en comunicación

Comscore (2020). Media Consumption during the Coronavirus Pandemic. Comscore. Recuperado de https://labur.eus/bPP2i

Deogracias, M. (2015). Idatzizko albisteen ikus- entzunezkotzea: Wall Street Journal, New York Times, El Pais, Ara, El Correo, Berria, Argia eta Goiena aztergai. Uztaro, 95, 73-96.

European Audiovisual Observatory (2020). Key Trends 2019-2020 Report. EAO. Recuperado de https://labur.eus/8ns0i

Encuesta Fácil, S.L. (2005-2020). EncuestaFacil.com. Recuperado de https://www.encuestafacil.com/

Evans, E. (2011). Transmedia television: Audience, new media and daily life. Londres: Routledge.

Feixa, C. (2000). Generación@. La juventud en la era digital. Nómadas, 13, 75-91. Recuperado de https://www.redalyc.org/pdf/1051/105115264007.pdf

Feixa, C. (2014). De la Generaxión@ a la \#Generación. Barcelona: Ned.

Flores-Ruiz, I. \& Humanes-Humanes, M.L. (2014). Hábitos y consumos televisivos de la generación digital desde la perspeciva de los usos y grafificaciones. Estudio de caso en la Universidad Rey Juan Carlos. Revista Mediterránea de Comunicación, 5(1), 137-155. doi: 10.14198/MEDCOM2014.5.1.06

Garitaonandia, C. et al. (2019). La convergencia mediática, los riesgos y el daño online que encuentran los menores. Doxa Comunicación, 28, 1-22. doi: $\underline{10.31921 / \text { doxacom.n28a10 }}$

Gevers, A. (2020a). Coronavirus pandemic and online behavioural shifts. Comscore. Recuperado de https://labur.eus/yQaqY

Gevers, A. (2020b). Coronavirus pandemic and online behavioural shifts. Comscore. Recuperado de https://labur.eus/RN971

González, O. (2018). Análisis de la narrativa audiovisual de los Youtubers y su impacto en los jóvenes colombianos. (Tesis doctoral). Universidad de Málaga, Málaga.

González Aldea, P. \& López Vidales, N. (2011). La generación digital ante un nuevo modelo de televisión: contenidos y soportes preferidos. Análisi, 31, 83-90. Recuperado de https://www.raco.cat/index.php/Analisi/article/view/248760

Gray, J. \& Lotz, A.D. (2012). Television studies. Cambridge: Polity Press. 
Pandemia, consumo audiovisual y tendencias de futuro en comunicación

Ihlebaek, K.A., Syvertsen, T. \& Ytreberg, E. (2013). Keeping Them and Moving Them: TV Scheduling in the Phase of Channel and Platform Proliferation. Television \& New media, 15(5), 470-486.

Ikusiker (2020). COVID-19 berrogeialdiak informazio eta komunikazio teknologien erabileran eta ikus-entzunezko edukien kontsumoan izandako eragina (La influencia del COVID-19 en los consumos audiovisuales y el uso de las TIC). Ikusiker. Recuperado de https://labur.eus/ZrMaY

Instituto IMOP (2020).. Los medios en la crisis del coronavirus. IMOP Insights. (Informes número 1 a 10). Recuperado de https://labur.eus/P3TIY

Jenkins, H. (2008). Convergence Culture: La cultura de la convergencia de los medios de comunicación. España: Paidós Ibérica.

Kalogeropoulos, A. (2020). News avoidance varies greatly for country to country. Why? Reuters Institute. Recuperado de https://labur.eus/7d2cS

Kantar Media (2020). Cómo han cambiado los hábitos de consumo de TV durante el COVID-19. Kantar Media. Recuperado de https://labur.eus/Huiv9

Labelium (2020). Era pos-COVID-19: Nuevos hábitos de consumo en el entorno audiovisual digital. Labelium. Recuperado de https://labur.eus/sQt5w

Landabidea, X. (2013). Belaunaldien telebistarekiko aisiazko harremanak: Bizkaiko lau adin-talderen kasu azterketa. (Tesis doctoral). Universidad de Deusto, Bilbao.

Li, F. \& Lalani, F. (2020). The COVID-19 pandemic has changed education forever. This is how. World Economic Forum. Recuperado de https://www.weforum.org/agenda/2020/04/coronavirus-education-global-covid19online-digital-learning/

Livingstone, S. \& Bober, M. (2004) UK children go online: surveying the experiences of young people and their parents. Londres: London School of Economics and Political Science.

Livingstone, S \& Sefton-Green, J. (2016. Parenting for a digital future: how parents' hopes and fears about technology shape childres's lives. Nueva York: Oxford University Press.

Lorenzo, A. (19 de marzo de 2020). Netflix rebaja su calidad de 'streaming' para preservar la sostenibilidad de Internet. El Economista. Recuperado de https://labur.eus/|1D7| 
Pandemia, consumo audiovisual y tendencias de futuro en comunicación

Lozano, C. (2018). Un adelanto sobre los retos y tendencias en la investigación de audiencias. Investigación y Marketing, 141, 23-25. Recuperado de https://labur.eus/QtEJp

Madinaveitia, E. (2020). Experimento general con todo: los medios y la publicidad en el confinamiento. En El Vigía. Recuperado de https://labur.eus/ue81P

Martinez, E. (2019). Alfabetización audiovisual en tiempo de la imagen digital. AulaPlaneta. Recuperado de https://labur.eus/EgTUD

Molay, A. \& Essling, I. (2020). Comscore Sees Shifting Category Trends for Digital Audiences Amid Pandemic. Comscore. Recuperado de https://labur.eus/7Q6Gm

Narbaiza, B. (2020). Gazteen kontsumoa COVID-19ren garaian. Euskal Hedabideen Behategia. Recuperado de https://labur.eus/MjfOV

Netflix (2020). 2020 Quarterly Earnings: First Quarter Earnings. Netflix. https://labur.eus/h4Ub0

Nielsen et al. (2020). Navigating the 'infodemic': how people in six countries access and rate news and information about coronavirus. Reuters Institute. Recuperado de https://labur.eus/UEQxv

OMS-Organización Mundial de la Salud (2020). Gestión de la infodemia sobre la COVID-19: Promover comportamientos saludables y mitigar los daños derivados de la información incorrecta y falsa. OMS. Recuperado de https://labur.eus/4i2Bv

Pavón-Arrizabalaga, A. (2014). Audiovisual teen and peer group consumption in 2011: a case study from Gipuzkoa. (Tesis doctoral). Mondragon Unibertsitatea, Aretxabaleta.

Pérez-Dasilva, J.A. et al. (2020). Fake news y coronavirus: detección de los principales actores y tendencias a través del análisis de las conversaciones en Twitter. Profesional de la información, 29 (3), 1-22. doi: 10.3145/epi.2020.may.08

Prado, E. (2009). Retos de la convergencia digital para la televisión. Quaderns del CAC, 31-32, 33-45. Recuperado de https://labur.eus/iEYOU

Prado, E. (2017): "Desafios para la diversidad audiovisual en Internet". En Albornoz y García Leiva (Eds.), El Audiovisual en la era digital (pp.161-191). Madrid: Cátedra.

Puente, H. et al. (2015). Los estudios sobre jóvenes y TICs en España. Revista de Estudios de Juventud, 110, 155-172. Recuperado de https://labur.eus/syNZb

Ramos, R. \& Pac, D. (2019). La juventud como early adopter del cambio tecnológico: un análisis de los jóvenes aragones (España). Sociologia, Problemas e Praticas, 91, 113. Recuperado de https://journals.openedition.org/spp/6365 
Pandemia, consumo audiovisual y tendencias de futuro en comunicación

Rivas, C. (2020). La Inversión Publicitareia cae un $-27,9 \%$ en el primer semestre de 2020. Infoadex. Recuperado de https://labur.eus/mF2fQ

Rogers, E. (1983). Diffusion on Innovations. Nueva York: The Free Press.

Rubio, A. (2010). Generación digital: patrones de consumo de Internet, cultura juvenil y cambio social. Revista de estudios de juventud, 88, 201-221. Recuperado de https://labur.eus/YoCUG

Sabater, C. (2014). La vida privada en la sociedad digital. La esposición pública de los jóvenes en Internet. Revista de Ciencias Sociales, 61, 1-32. Recuperado de https://www.redalyc.org/pdf/4959/495950257001.pdf

Salaverria, R. (2019). Digital first (but not 'only'): Un preludio triste y 8 tendencias de futuro. Bizkaiko Publizitatea Agentzien Elkartea. Recuperado de https://labur.eus/aKRLh

Sandvine (2020). The Global Internet Phenomena Report. Sandvine. Recuperado de https://labur.eus/6Ggif

Sanz, J.L. (2020). Cómo ver contenidos en grupo ahora que estamos en cuarentena (HBO, Prime Vidoeo, etc.). El País. Smart TV. Recuperado de https://labur.eus/hRR1I

Scolari, C. (2013). Narrativas transmedia: cuando todos los medios cuentan. Barcelona: Deusto.

Serrano-Puche, J. (2013). La educación mediática en la era de la hiperconectividad: una apuesta por la desconexión digital periódica. Actas del Congreso Internacional Educación mediática \& Competencia digital. Barcelona: IN3 y UOC. Recuperado de https://labur.eus/yMXDe

Statista (2020). Netflix suma más abonados que nunca impulsado por el coronavirus. Statista. Recuperado de https://labur.eus/pevRi

The Social Media Family (2020). VI Estudio sobre los usuarios de Facebook, Twitter e Instagram en España. The Social Media Family. Recuperado de https://labur.eus/IAIOY

Trescom (2020). I Estudio digital sobre plataformas streaming en España. Recuperado de https://labur.eus/jCtRk

Tubella. I., Tabernero, C. \& Dwyer, V. (2008). Internet i televisió: la guerra de les pantalles. Barcelona: UOC.

Zallo, R. (2016). Tendencias en comunicación: cultura digital y poder. Barcelona: Gedisa. 
Pandemia, consumo audiovisual y tendencias de futuro en comunicación

\section{AUTORES}

\section{Edorta Arana Arrieta.}

Licenciado en Periodismo (1982) y doctor en Comunicación Audiovisual (1995). Fue periodista en ETB. Desde 1988 es profesor e investigador en la UPV/EHU.

Imparte asignaturas sobre la programación en radio, televisión e Internet y su oferta, contenido y evaluación de audiencia. Ha publicado varios libros y artículos sobre programación. La investigación la ha dirigido al estudio de la influencia de los medios de comunicación en la identidad y la lengua; los medios digitales y sus audiencias; el análisis y realización de producciones transmedia y, ahora, en la medición y análisis de audiencia a través de los paneles de usuarios. Es miembro del grupo de investigación NOR y trabaja en varios proyectos de investigación del MINECO y la UPV/EHU.

Orcid ID: https://orcid.org/0000-0002-6171-6534

\section{Libe Mimenza Castillo.}

Licenciada en Comunicación Audiovisual y doble Máster en Comunicación Multimedia y Comunicación Social por la UPV/EHU. Actualmente está preparando su tesis doctoral sobre la evolución y desarrollo de la prensa en euskera en los distintos soportes digitales. Es miembro del grupo de investigación NOR y ha participado en distintos proyectos de investigación sobre nuevas tecnologías, redes sociales y producción transmedia. Ha publicado un número importante de artículos y capítulos de libros y ha participado en congresos internacionales. Actualmente está contratada como investigadora en la UPV/EHU y es la responsable del Observatorio de los medios de comunicación en euskera (Behategia). Es además la editora del Anuario de la comunicación en euskera publicado por dicho Observatorio.

Orcid ID: https://orcid.org/0000-0002-4944-824X

\section{Beatriz Narbaiza Amillategi.}

Licenciada en Periodismo (1991) y doctora en Comunicación Audiovisual (2016). Es profesora e investigadora en la UPV/EHU desde 1996. Antes trabajó como redactora y realizadora de televisión en Goiena TB y ETB. Imparte asignaturas relacionadas con la realización audiovisual. Es la responsable del Master en Comunicación Multimedia de la UPV/EHU. Forma parte del grupo de investigación NOR y participa en dos proyectos de investigación sobre consumos audiovisuales y uso de las tecnologías de la información y la comunicación, mediante el panel de usuarios (UPV/EHU) y la convergencia entre movimientos sociales en el País Vasco (MINECO). Anteriormente, ha participado en proyectos de investigación sobre producción y narrativa transmedia ("Korrika", "Emusik" y "Tirabirak"). Ha publicado numerosos artículos y participado en congresos internacionales.

Orcid ID: https://orcid.org/0000-0001-9537-6163 